\title{
Genome editing in cultured fishes
}

\author{
Eric Hallerman * (B)
}

\begin{abstract}
With external fertilization, high fecundity, and established methods for propagation and larval rearing for cultured species, fish provide systems well suited to genome-editing procedures. While early experiments utilized zinc-finger nucleases and transcription activator-like effector nucleases (TALENs), most recent ones have used the CRISPR/Cas9 editor, and achieved rates of targeted genomic insertion well above those of classical transgenic methods, with lower frequencies of off-site integration. Genome-editing experiments with cultured fishes have focused on improving growth rate and disease resistance, achievement of reproductive confinement, and other valued traits. As reviewed here, advances in knowledge of key molecular pathways and, in some cases, favorable alterations of phenotype have been achieved. For example, loss-of-function of myostatin, a negative regulator of muscle growth, led to increased muscle mass, greater weight, and greater fillet yield in genome-edited lines of red sea bream, tiger puffer, and Nile tilapia than in their unedited counterparts. The red sea bream line become the first genome-edited animal to reach commercial production. As for all animals, wide adoption of genome-edited fishes will depend upon addressing issues of regulation, consumer acceptance, and breeding infrastructure.
\end{abstract}

Keywords: Aquaculture, Growth promotion, Disease resistance, Reproductive confinement, CRISPR/Cas9

\section{Introduction}

Aquaculture, the controlled production of aquatic and marine organisms, makes an important contribution to the world supply of fisheries products. That contribution has grown from $4 \%$ of world fisheries products in 1970 to over half today (Fig. 1), a growth rate of approximately 5.3\% annually from 2001 to 2018 (FAO 2020). Aquaculture products are important to human nutrition, especially in developing countries, contributing a large part of the protein consumed. Aquaculture employs 20.5 million people globally, $85 \%$ of them in Asia (FAO 2020).

Intensification of aquaculture production would contribute to human well-being. Intensification can be achieved by improving production systems and, more critical to the scope of this review, by genetic improvement of the farmed types (Mair and Lucente 2020). Selective breeding of aquaculture species has achieved notable successes, including Donaldson strain rainbow trout Oncorhynchus mykiss (Donaldson and Olson 1957), Norwegian Atlantic salmon Salmo salar (Thodesen and Gjedrem 2006), and Genetically Improved Farmed Tilapia (GIFT) Oreochromis niloticus (Ponzoni et al. 2011). Further production value can be added by contributions from biotechnology, including development of monosex, triploid, genetically modified (Dunham 2011) and genome-edited stocks. The application of genome-editing tools to improvement of cultured fishes is the focus of this literature review and synthesis. Genome editing of fishes has been reviewed by Barman et al. (2017), Zhu and Ge (2018), Wargelius (2019), Gratacap et al. (2019), Blix et al. (2021), and Yang et al. (2022). My objectives are to provide an update on technical progress in genome editing of cultured fishes, and to characterize regulatory, consumer acceptance, and infrastructural issues facing the adoption of genome-edited lines by the commercial aquaculture sector.

*Correspondence: ehallerm@vt.edu

Department of Fish and Wildlife Conservation, Virginia Polytechnic

Institute and State University, Blacksburg, VA 24061, USA

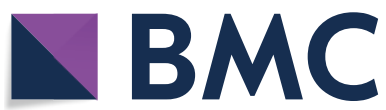

(c) The Author(s) 2021. Open Access This article is licensed under a Creative Commons Attribution 4.0 International License, which permits use, sharing, adaptation, distribution and reproduction in any medium or format, as long as you give appropriate credit to the original author(s) and the source, provide a link to the Creative Commons licence, and indicate if changes were made. The images or other third party material in this article are included in the article's Creative Commons licence, unless indicated otherwise in a credit line to the material. If material is not included in the article's Creative Commons licence and your intended use is not permitted by statutory regulation or exceeds the permitted use, you will need to obtain permission directly from the copyright holder. To view a copy of this licence, visit http://creativecommons.org/licenses/by/4.0/. The Creative Commons Public Domain Dedication waiver (http://creativeco mmons.org/publicdomain/zero/1.0/) applies to the data made available in this article, unless otherwise stated in a credit line to the data. 


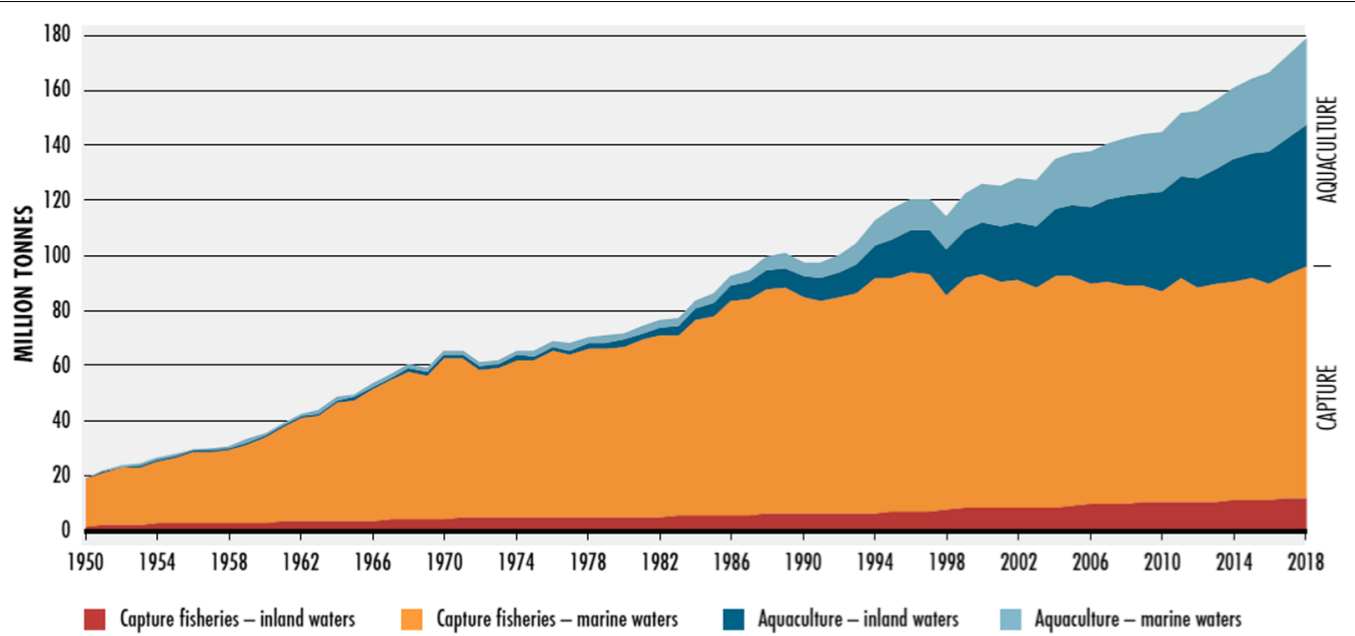

Fig. 1 Growth of world aquaculture (FAO 2020)

\section{Progress in applying genome editing methods to fishes}

Fishes have high fecundity, ranging from hundreds (tilapias) to thousands (most freshwater fishes) to many thousands (most marine fishes) of eggs per ovulation. Protocols for artificial induction of spawning exist for many cultured species. Fertilization of eggs is external, and easily conducted in vitro. The eggs are large relative to those of mammals, and are amenable to microinjection, electroporation, or other protocols to introduce DNA constructs. Embryonic and larval development occur outside the mother, and egg incubation and larval rearing methods are established for aquacultured species. For aquaculture species, generation times range from one (tilapias) to several (carps, salmonids, catfishes) years. These life-history and culture attributes are such that fishes provide systems highly suitable for genetic modifications, including genome editing.

\section{Proof of principle and application of alternative genome editing approaches}

Genome editing in fishes, as in any organism might be approached through use of zinc-finger nucleases, ZFNs (Bibikova et al. 2002, 2003), transcription activatorlike effector nucleases, TALENs (Boch and Bonas 2010) or CRISPR-Cas9 (Doundna and Charpentier 2014). Although ZFNs and TALENs made production of geneedited animals possible, they proved relatively difficult to engineer and showed relatively low specificity to target DNA sequences (Maggio and Goncalves 2015). The CRISPR/Cas9 (clustered regularly interspaced short palindromic repeats/CRISPR-associated protein 9) system originally was identified in bacteria and archaea, where it provides a defense against bacteriophages and foreign
DNA (Horvath and Barrangou 2010; Garneau et al. 2010; Wiedenheft et al. 2012). The CRISPR from Streptococcus pyogenes (Horvath and Barrangou 2010; Ran et al. 2013) and endonuclease Cas9 are introduced into a host cell with a synthetic small guide RNA (sgRNA) targeting a gene, creating a double-strand break in the DNA at a targeted site. All genome-editing tools employ sitedirected nuclease (SDN) technology to make a targeted DNA break. The host's non-homologous end-joining (NHEJ) or homology-directed repair (HDR) process religates the double-strand break. SDN applications are divided conceptually into three categories (NBT Platform 2014). SDN-1 produces a double-stranded break in the host genome without addition of foreign DNA. The spontaneous repair of this break can lead to a mutation or deletion, causing gene silencing, gene knock-out, or a change in the activity of a gene. SDN-2 produces a double-stranded break, and a small nucleotide template is supplied that is complementary to the area of the break, which in turn, is used by the cell to repair the break. The template contains one to several small sequence changes in the genomic code, which the host DNA repair mechanism copies into the host genome, resulting in a mutation of the target gene. SDN-1 and SDN-2 mutations can be as specific as the editing of a single base. SDN-3 also induces a double-stranded break in the DNA, but is accompanied by a template containing a gene or other sequence of genetic material. The cell's DNA repair system utilizes this template to repair the break, resulting in the introduction of new genetic material. As noted below, the distinction between these SDN categories likely will affect government oversight of animals produced by genome-editing technology and likely also public perception of applications of genome editing. 
Researchers seek new tools to improve editing efficiency and reduce the rate of off-target mutations, leading to development of a new class of genome editors call base editors. Base editors change one base to another without breaking the target DNA strand. The first-developed cytosine base editor converts a cytosine-guanine $(\mathrm{C}-\mathrm{G})$ base pair into a thymine-adenine (T-A) base pair (Komor et al. 2016). Shortly later, an adenine base editor was developed (Gaudelli et al. 2017) to transform A-T to C-G base-pairs. Subsequently, Anzalone et al. (2019) reported development of prime editing technology, which addresses the limitations of base editing; that is, prime editing implements all 12 types of base substitutions (eight base transversions, four base conversions), with a maximum of 44-base insertions and 80-base deletions. Base editors provide higher transformation efficiencies, about $40-50 \%$ for cell lines, and cause fewer off-target mutations than previous genome editors. Improved base editors are being developed at a rapid rate, and are being applied to correct point mutations in cell lines and animal model systems, with an eye to eventual use for clinical use in human systems (Ravindran 2019). Model systems notably include zebrafish Danio rerio (Zhang et al. 2017; Qin et al. 2018; Lu et al. 2021). To my knowledge, there are yet no reports of application of base editing techniques to aquaculture species. Unlike ZFNs and TALENs, for CRISPR/Cas9, the sgRNA is the only component that needs to be designed for each genomic target, simplifying the design and reducing the cost of genome editing. Hence, CRISPR/Cas9 has been applied in most recent studies of genome editing in fishes. The first genome-editing experiments in fishes used model systems such as zebrafish, first using ZFNs (Meng et al. 2008; Doyon et al. 2008), followed by the more efficient TALENS (Huang et al. 2011), and ultimately by CRISPR/ Cas9 (Hwang et al. 2013). CRISPR/Cas9 is so efficient that it can induce gene specific bi-allelic mutations in the first, $F_{0}$ generation (Jao et al. 2013), making this tool potentially useful for practical application in aquaculture species with longer generation times.

Attempting to create specific bi-allelic mutations in target genes in Atlantic salmon using the CRISPR/Cas9 system, Edvardsen et al. (2014) selected as markers genes producing pronounced pigmentation phenotypes. Oligonucleotides targeting the solute carrier family 45, member $2(s l c 45 a 2)$ and tyrosinase (tyr) genes that are be involved in pigmentation in zebrafish and other species were cloned into a CRISPR vector. The embryos were assayed for mutation rates at the 17 -somite stage, when 40 and $22 \%$ of all injected embryos showed mutations at slc $45 a 2$ and tyr, respectively. At hatch, the effects of mutations were readily visible for both targeted genes, displaying a range of phenotypes from complete lack of pigmentation, to partial loss, to normal pigmentation (Fig. 2), demonstrating that CRISPR/Cas9 can induce double-allelic knockout in the $\mathrm{F}_{0}$ generation. Because the types and frequencies of indels might affect phenotype, variation of indels was assayed among the graded pigmentation phenotypes produced by CRISPR/Cas9-editing of $s l c 45 a 2$. The results showed fewer types of indels in juveniles completely lacking pigmentation than in juveniles displaying partial pigmentation. Hence, targeted double-allelic mutations can be obtained, but mosaicism has to be considered.

In a variation of the common method of using mRNA injections, Qin et al. (2016) designed three sets of ZFN plasmids targeting the luteinizing hormone $(L H)$ gene and electroporated them at different concentrations into one-cell channel catfish Ictalurus punctatus embryos. The overall mutation rate was $19.7 \%$ for 66 channel catfish, and the most effective treatment used ZFN set 1 at a concentration $25 \mu \mathrm{g} / \mathrm{ml}$. This was the first instance of genome editing of fish via plasmid introduction, which

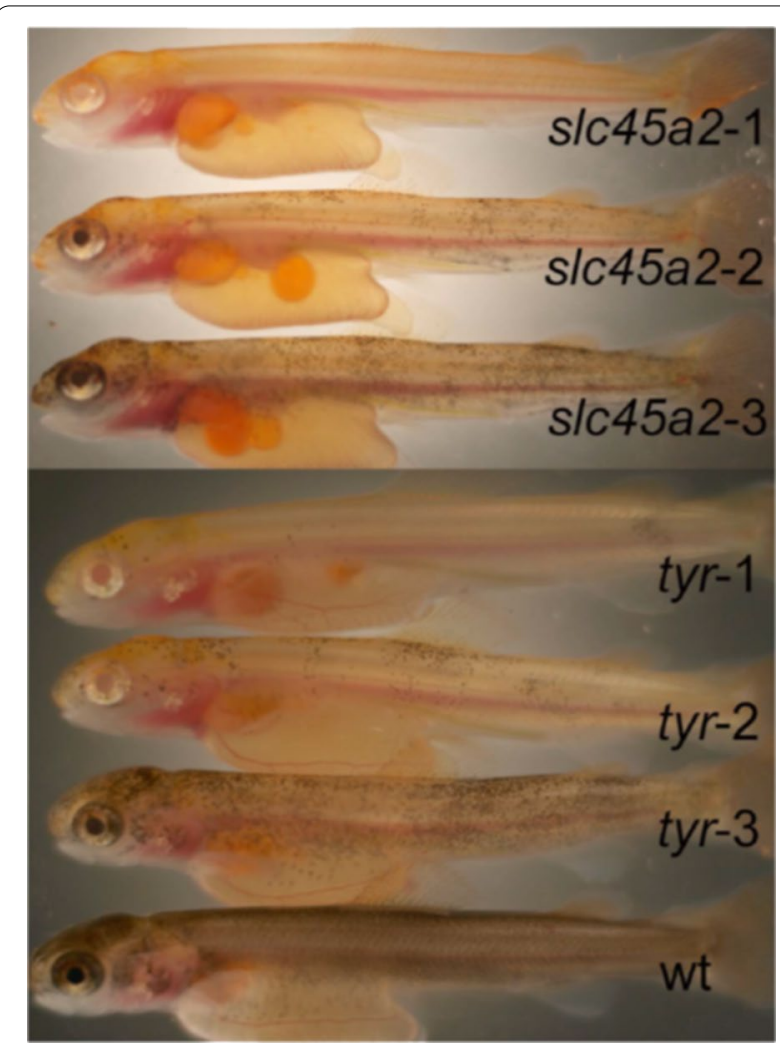

Fig. 2 Reduced pigmentation in larval Atlantic salmon modified by Edvardsen et al. (2014). The solute carrier family 45, member 2 (s/c45a2) and tyrosinase (tyr) genes are known to be involved in pigmentation in fishes. Forty and $22 \%$ of injected Atlantic salmon embryos showed mutations at s/c45a2 and tyr, shown at top and bottom, respectively, displayed phenotypes ranging from complete lack of pigmentation, to partial loss, to normal pigmentation 
may have reduced mosaicism, as mutated individuals were genome-edited in every tissue evaluated. Apparently, the plasmids were eventually degraded without integration, as they were not detectable in mutated individuals using PCR.

Marine fishes characteristically have high fecundity, but low larval survival. Effective genome editing in marine fishes will depend upon developing microinjection methods where eggs maintain their rate of survival and many can be treated. Kishimoto et al. (2019) investigated the effects of different isotonic solutions and elapsed time from stripping of gametes from broodstock and from fertilization to microinjection upon survival and numbers of tiger pufferfish Takifugu rubripes and red sea bream Pagrus major eggs treated. For pufferfish, Iwamatsu solution or diluted sea water was effective as the soaking solution, and fertilization could be performed at intervals of $15 \mathrm{~min}$ from fertilization until $2.5 \mathrm{~h}$ after stripping. For red sea bream, Leibovitz's L-15 medium or Iwamatsu solution was effective as the soaking solution and fertilization could be performed at intervals of $10 \mathrm{~min}$ from fertilization until $2.5 \mathrm{~h}$ after stripping.

Though microinjection is the most common method for manipulating fish embryos, it is not easy to inject the RNA into the small eggs of pelagic marine fishes with a hard egg chorion, such as olive flounder Paralichthys olivaceus. Wang et al. (2021) evaluated use of electroporation and the CRISPR/Cas9 system to edit different genes, myomaker and gonadal soma derived factor ( $g s d f)$. With electroporation at 3 pulses for $1 \mathrm{~ms}(\mathrm{~ms})$ with a 50 -ms interval at $25 \mathrm{~V}$, around $12 \%$ and $7 \%$ of the electroporated embryos for myomaker and gsdf hatched, respectively. Both insert and deletion mutations at the candidate sites were observed for both targeted genes in the hatched larvae. The observed frame-shift and start-codon deletion mutations would lead to complete knockout of gene expression. Using CRISPR/Cas9 and electroporation, genome editing could be achieved on a large scale, which may prove useful for marine fishes.

Improving the efficiency of precise genome editing in founder individuals is more important than obtaining a high number of mosaic $F_{0}$ fish; hence, recent methodological work has focused on how to optimize editing protocols. CRISPR/Cas9-mediated gene knockouts are produced by a Cas9-induced double-stranded DNA break followed by activation of the endogenous, errorprone non-homologous end joining (NHEJ) pathway, which introduces indels at the repair junction. Especially for fishes or other animals with a long generation time, investigators would want to study the effects of gene knockout in the $\mathrm{F}_{0}$ generation; however, mosaicism caused by NHEJ may include partly functional in-frame indels that affect the result. Better-controlled insertions utilizing the homology directed repair (HDR) mechanism might instead be used to effectively insert a stop codon. Double strand break repair by HDR can occur by several pathways, such as synthesis-dependent strand annealing, or by the formation of Holliday junctions that can be resolved with or without crossing-over. Straume et al. (2020) performed knock-in of a FLAG element in the slc45a2 gene in Atlantic salmon using sense, anti-sense, and double-stranded oligodeoxynucleotide (ODN) templates with short $(24,48$, or $84 \mathrm{bp})$ homology arms. They observed ODN integration in almost all of the genomeedited animals, including perfect HDR rates of up to $27 \%$ in individual $\mathrm{F}_{0}$ embryos, much higher than reported previously in any fish. HDR efficiency was dependent on template concentration, but not homology arm length. Analysis of imperfect HDR variants suggested that repair occurs by synthesis-dependent strand annealing, with indel location dependent on template polarity. Correct ODN polarity can be used to avoid $5^{\prime}$-indels interrupting the reading frame of an inserted sequence and could be important for HDR template design. Straume et al. (2021) aimed to further improve the HDR precision and efficiency, aiming to reduce mosaicism in individual $\mathrm{F}_{0}$ animals. Asymmetrical ODNs in combination with CRISPR/Cas9 have been shown to improve HDR rates in cell cultures and induced pluripotent stem cells. They showed that asymmetrical oligonucleotide donors induced highly efficient and precise edits in individual Atlantic salmon founder animals. They performed single nucleotide replacement in the dead end $(d n d)$ gene with up to $59.2 \%$ efficiency, and inserted FLAG elements into $s l c 45 a 2$ and $d n d$, with up to $36.7 \%$ and $1932.7 \%$ efficiency, respectively. HDR efficiency was dependent on template concentration, but there was a trade-off with respect to toxicity.

Before genome-edited fishes can enter routine commercial production, technical issues of off-target mutation and mosaicism in the founder $F_{0}$ generation must be resolved. Although genome editors are designed to target particular genomic sequences in the host, mutations also can affect untargeted locations. Such off-target mutations are the result of the editor's guide RNA annealing to non-targeted sequences in the genome, initiating mutations that might lead to unknown or unintended effects upon the host, such as change in gene activity, gene silencing, or gene knockout (Kosicki et al. 2018). High rates of embryo mortality (Qin et al. 2016; Elaswad et al. 2018; Simora et al. 2020) or malformation (Baloch et al. 2019) observed in some studies may have been the consequence of off-target mutations. Such off-target mutations can prove difficult to detect because the number and site of nucleotide changes are unknown to the investigator. The specificity of annealing of a guide RNA to host DNA 
may be the critical factor driving the frequency of off-target effects; Elaswad et al. (2018) suggest that a guide RNA with as many as five mismatching guide RNA nucleotides could still anneal to a host sequence. Off-target effects may be minimized by careful design of the guide RNA by comparing the candidate guide RNAs to established genome assemblies; this approach has been applied in some fish genome-editing studies date (e.g., Wargelius et al. 2016; Zhong et al. 2016; Kishimoto et al. 2018, and others-see Blix et al. 2021), although reference genomes may be sparse or absent for some cultured species. Elaswad et al. (2018) suggest the use of Cas9 nickase with paired guide RNAs to reduce off-target effects. Mosaicism for a mutation may occur in founder individuals due to delayed induction of the mutation during embryogenesis. An approach to recognizing off-target mutations and mosaicism in founder individuals would be routine rescreening of the genome for discovery of new mutations. Application of this approach is complicated, however, by natural DNA sequence variation within the species, which by making comparator sequences unclear, makes it difficult to definitively identify off-target effects. Blix et al. (2021) provide a more thorough consideration of off-target effects in genome-edited finfishes. They suggested broader use of next-generation sequencing and multiple -omics approaches to distinguish natural DNA sequence variation and the effects of mutations induced by genome editing.

As jawless vertebrates, studies of lamprey development and gene function provide insight into development of the cranium and morphologies unique to vertebrates, such as the neural crest, brain, pharyngeal skeleton, jaw, vertebrae and appendages. Techniques for transformation of lampreys had not been established, and methods to generate mutations through germ-line transmission would be difficult to implement, as lampreys have a complex life cycles and take up to 20 years to reach sexual maturation. $\mathrm{Zu}$ et al. (2016) developed a CRISPR/ Cas9 system optimized for lamprey genomes and used it to edit loci in Northeast Chinese lamprey Lethenteron morii. Frequencies of indels observed at the target loci golden (gol), kctd10, wee1, soxe2, and wnt7b estimated from direct sequencing of genomic DNA from injected lamprey larvae ranged from 84 to $99 \%$. These indels often occurred in both alleles. Following editing of gol and kctd $10,38.6 \%$ and $85.3 \%$ of the targeted larvae exhibited reduced retinal pigmentation and heart malformation, respectively. Genome editing thus has the potential for efficient genetic perturbation in organisms less amenable to gene manipulation, which could facilitate studies of development studies in additional model systems.

While sturgeons produce highly valued eggs and meat, selective breeding is limited by their long generation time, usually $6-12$ years for males and $10-18$ years for females. Hence, there is interest in applying genomeediting techniques to achieve targeted modifications rapidly. Chen et al. (2018) developed gene transfer and genome-editing techniques for sterlet Acipenser ruthenus. Following classical gene transfer of the enhanced green fluorescent protein $(E G F P)$ gene, it was efficiently disrupted by use of TALENs or CRISPR/Cas9 systems. The endogenous no tail gene in sterlet was edited using CRISPR/Cas9, with mutant $\mathrm{P}_{0}$ embryos displaying the expected phenotypes of bent spine and twisted tail. Efficient mutation of endogenous genes in tetraploid starlet suggested the utility of the CRISPR/Cas9 system in in other sturgeon species with hexaploid or octoploid genomes.

\section{Enhancement of growth and muscular development}

While genetic improvement programs may have multiple breeding goals, rapid growth rate is universally valued. Some programs also target greater investment in the musculature, the portion of the fish that is ultimately consumed.

Myostatin is a key regulator of skeletal muscle growth in all vertebrates and regulates myoblast differentiation in vitro. Expression of myostatin ( $m s t n)$, or growth and differentiation factor 8 , is linked with the so-called "double-muscled" phenotype in Belgian Blue and Piedmontese cattle, resulting in a significant increase in muscling compared to breeds lacking the causal mutation (Grobet et al. 1998). Mstn knockout in mice led to increased muscle mass (McPherron et al. 1997). The mstn protein is conserved in teleost fishes, but its functions in fishes were unknown because of the lack of spontaneous mstn null mutations. Knockout of mstn contributed to understanding of the roles of this gene in fishes and could contribute to purposeful alteration of phenotype. Genome-editing experiments have targeted the myostatin gene of several cultured fishes.

Yellow catfish Pelteobagrus fulvidraco is one of the most important freshwater aquaculture species in China, and hence worldwide (Table 1). However, small size and low fillet yield limit its value. To assess the role of $m s t n$ expression on growth and seeking to create a strain of yellow catfish with heightened muscle mass, Dong et al. (2011) targeted disruption of the mstn gene using zincfinger nucleases (ZFNs). Using zebrafish embryos as a screening system, they obtained a pair of ZFNs that could edit mstn. Using the ZFNs, they produced two yellow catfish founders carrying a mutated mstn gene in their germ cells. Founder July29-7 had a 4-bp insertion, predicted to encode functionally null mstn. Founder July29-8 carried a complex mutation, predicted to encode a protein lacking two amino acids in the $\mathrm{N}$-terminal secretory 
Table 1 Animal species important to aquaculture, ranked by contribution in percent to world finfish production (FAO 2020; contributions do not add to 100\% because species groups are not here included), and traits approached using genome editing

\begin{tabular}{|c|c|c|c|c|c|}
\hline Species or group & $\begin{array}{l}\text { Share of } 2018 \\
\text { production }\end{array}$ & $\begin{array}{l}\text { Growth, muscle } \\
\text { development }\end{array}$ & $\begin{array}{l}\text { Reproductive } \\
\text { confinement }\end{array}$ & $\begin{array}{l}\text { Disease } \\
\text { resistance }\end{array}$ & Other trait \\
\hline Grass carp, Ctenopharyngodon idellus & 10.5 & & & $x$ & \\
\hline Silver carp, Hypophthalmichthys molitrix & 8.8 & & & & \\
\hline Nile tilapia, Oreochromis niloticus & 8.3 & $x$ & $x$ & & \\
\hline Common carp, Cyprinus carpio & 7.7 & $x$ & & & \\
\hline Bighead carp, Hypophthalmichthys nobilis & 5.8 & & & & \\
\hline Catla, Catla catla & 5.6 & & & & \\
\hline Crucian carps, Carassius spp. & 5.1 & & & & Coloration \\
\hline Atlantic salmon, Salmo salar & 4.5 & & $x$ & & Coloration, fatty acid metabolism \\
\hline Striped catfish, Pangasianodon hypophthalmus & 4.3 & & & & \\
\hline Rohu, Labeo rohita & 3.7 & & & $x$ & \\
\hline Milkfish, Chanos chanos & 2.4 & & & & \\
\hline Torpedo-shaped catfishes, Clarias spp. & 2.3 & & & & \\
\hline Rainbow trout, Oncorhynchus mykiss & 1.6 & $x$ & & & \\
\hline Wuchang bream, Megalobrama amblycephala & 1.4 & & & & \\
\hline Black carp, Mylopharyngodon piceus & 1.3 & & & & \\
\hline Yellow catfish, Pelteobagrus fulvidraco & 0.9 & $x$ & & & \\
\hline Channel catfish, Ictalurus punctatus & - & $x$ & $x$ & $x$ & \\
\hline Large-scale loach, Paramisgurnus dabryanus & - & & & & Coloration \\
\hline Olive flounder, Paralichtyhs olivaceaous & - & $x$ & & & \\
\hline Pacific bluefin tuna, Thunnus orientalus & - & & & & Swimming behavior \\
\hline Pacific oyster, Crassostrea gigas & - & & & & Myosin function \\
\hline Red sea bream, Pagrus major & - & $x$ & & & \\
\hline Ridgetail white prawn, Exopalaemon carinicauda & - & & & & Chitinase function \\
\hline Southern catfish, Silurus meridionalus & - & & $x$ & & \\
\hline Tiger pufferfish, Takifugu rubripes & - & $x$ & & & \\
\hline
\end{tabular}

signal. In total, they obtained six mstnnju6/+ and fourteen mstnnju7/+ yellow catfish. Zhang et al. (2020) subsequently reported that the genome-edited mstna yellow catfish grew and bred normally. Both male and female homozygous mutants displayed two obvious muscle masses between the head and dorsal fin at 1-monthold (Fig. 3b), which become more obvious with growth. The body weight of mstna-null yellow catfish was 1.271.37-fold higher than their wild-type siblings at 80 and 210 days post-fertilization. Histological analysis revealed that the mstna-knockout yellow catfish had increased numbers of fibers, but decreased fiber size in skeletal muscle (Fig. 3c).

Dong et al. (2014) reported identification of a second myostatin gene, mstnb, and its knockout in yellow catfish. The gene comprises three exons, and is predicted to encode 373 amino acid residues with $59.3 \%$ identity with yellow catfish MSTNa. After employing TALENs, four randomly selected founders exhibited six mutated mstnb alleles, four with non-frameshift and two with frameshift mutations. The frameshift-mutated alleles included mstnbnju22, an 8-bp deletion, and mstnbnju24, a complex mutation comprising a 7-bp deletion and a 12-bp insertion, which were predicted to encode functionally null MSTNb. The authors obtained two founders carrying the mutated mstnb gene in their germ cells.

Common carp Cyprinus carpio is cultured in more than 100 countries, with annual production of approximately 3.7 million metric tons (FAO 2020). The presence of inter-muscular bones prevents it from being more widely popular. Zhong et al. (2016) employed TALEN and CRISPR/Cas9 to target bone and muscle developmentrelated genes. In the bone formation pathway, $b m p 2 a$ is an upstream gene, $r u n x 2$ and $s p 7$ are midstream genes, spp 1 is a downstream gene, and opg inhibits osteoclast formation. Myostatin mstn is involved in muscle formation. TALENs were shown to induce mutations in the targeted coding sites of the $s p 7, \operatorname{run} x 2$, spp1, and mstn genes. CRISPR-Cas9 was used to separately target the two $s p 7$ genes, $s p 7 a$ and $s p 7 b$. Mutations in bone-formation-related genes resulted in severe bone defects. The mstn-mutated fish had significantly more muscle cells. 

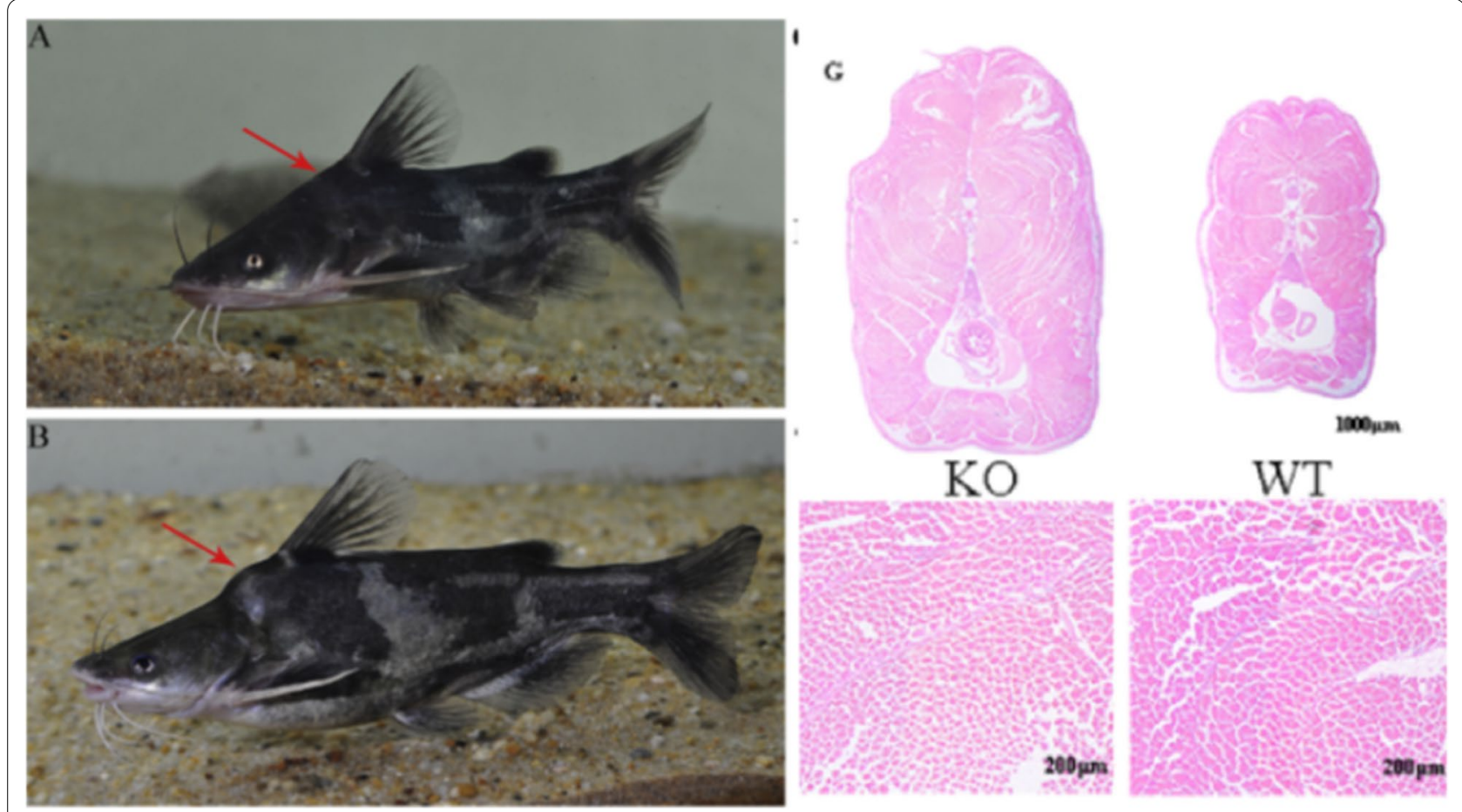

Fig. 3 Yellow catfish exhibiting wild-type (A) and edited myostatin a (B) phenotypes (Dong et al. 2011). The homozygous mutants displayed double-muscling, with two obvious muscle masses between the head and dorsal fin at 1-month-old, which become more obvious with growth. $\mathbf{C}$ Histological sections showed that mstna-knockout fish had increased numbers of fibers, with decreased fiber size

The results demonstrated the effectiveness of TALEN and CRISPR/Cas9 for targeted modification of the tetraploid common carp genome, although the bone development-related modification likely will not prove useful for practical genetic improvement.

Channel catfish is an important aquaculture species in the United States, with annual production of $\sim 136$ million kg per year (USDA-NASS 2018). Khalil et al. (2017) used CRISPR/Cas9 to target the channel catfish mstn gene and induced $88-100 \%$ rates of mutagenesis in its protein-encoding sites. Mstn-edited fry had more muscle cells $(p<0.001)$ than controls, and the mean body weight of gene-edited fry increased by $29.7 \%$. Alignments of DNA sequences among mutated and wild-type fish revealed multiple insertions and deletions. Further study is needed to evaluate carcass composition and meatquality traits of mutated individuals at commercial food size (400-700 g), and other physiological and immune traits would have to be considered and linked to the productivity of genome-modified lines.

Olive flounder Paralichthys olivaceus is a commercially important fish species in Korea, China, and Japan. Kim et al. (2019) edited its mstn gene using the CRISPR/Cas9 system following microinjection of 1-cell or 2-cell stage embryos. On-target mutations on the mstn locus were generated in somatic tissues with $75.6 \%$ efficiency, and $\mathrm{F}_{0}$ founders harboring germline mutations were produced. Restriction fragment length polymorphism analysis was applied to select biallelic mutants in the $F_{1}$ generation, and heterozygous biallelic mutants with mstn disruption were obtained. Mstn-disrupted olive flounders exhibited greater body thickness and increased condition factor, indicating increase of muscle mass with muscle hyperplasia. Expression of mstn mRNA and protein was significantly reduced in the muscle of genome-edited fish, and mRNA expression of the major myogenic regulatory factors myogenin, $M y o D$, and $M y f 5$ was differentially affected in mstn-disrupted mutants.

Red sea bream Pagrus major is an important aquaculture fish in Japan. Using CRISPR/Cas9, Kishimoto et al. (2018) demonstrated complete mstn knockout. The mutations were deletions in the first exon of the mstn gene, which caused disruption of the C-terminal active domain of MSTN. The fish showed a 16\% increase of skeletal muscle, as well as short body length and small centrum, which was not observed in studies of other teleost fishes. They established the homozygous, genedisrupted line in 2 years, which was shorter than possible using conventional breeding. Ohama et al. (2020) subsequently performed a feeding trial and characterized growth rate, feed conversion efficiency, and whole-body proximate analysis. Weight gain, specific growth rate, and 
feed efficiency were significantly higher in the homozygous mutant (HM) group than that in the wild-type (WT) group, and there was no significant difference in the daily feed intake. The protein efficiency and apparent protein retention were significantly higher in HM than in WT. While HM fish fed similarly to WT fish during the juvenile stage, HM fish had a higher ability to convert feed efficiently and accumulate ingested protein, resulting in better overall growth.

The U.S.-based company AquaBounty has developed a Nile tilapia Oreochomus niloticus FLT-01 line with a 26-bp deletion in its myostatin gene, creating an early stop codon. Loss of function of myostatin led to increased muscle mass, greater weight, and greater fillet yield than its unedited counterpart (M. Walton, AquaBounty, pers. comm). The FLT-01 line was created using microinjection with nuclease mRNA; no introduction of DNA was involved. The final product is homozygous for the 26-bp deletion, and there are no off-target sites of modification.

The growth hormone $(\mathrm{GH})$-insulin-like growth factor (IGF)-I axis is a positive regulator of growth in vertebrates, including fishes. The IGF-binding proteins (IGFBP) prolong the half-life of IGF-I in circulation and regulate the availability of IGFs to target specific tissues. In salmonid fishes, the majority of circulating IGF-I is bound to IGF-binding proteins (IGFBP), with IGFBP$2 \mathrm{~b}$ the most abundant in circulation. Cleveland et al. (2018) CRISPR/Cas9 to disrupt expression of a functional IGFBP-2b protein by co-targeting for gene editing both IGFBP-2b1 and IGFBP-2b2 subtypes, which represent salmonid-specific gene duplicates in the tetraploid salmonids. Twenty-four rainbow trout Oncorhynchus mykiss were produced with mutations in the $I G F B P-2 b 1$ and IGFBP-2b2 genes. Mutant fish exhibited between $8-100 \%$ and $2-83 \%$ frequencies of gene disruption for IGFBP-2b1 and IGFBP-2b2, respectively, with a positive correlation $(p<0.001)$ in gene mutation rate between individual fish. Analysis of IGFBP-2b protein indicated reductions in plasma IGFBP-2b abundance to between 4 and $96 \%$ of control levels. Plasma IGF-I, body weight, and fork length were reduced in mutants at 8 and 10 months after hatch, which supports the interpretation that IGFBP-2b is important for carrying IGF-I. Despite reduced plasma IGF-I and IGFBP-2b in mutant individuals, growth retardation in mutants was less severe between 10 and 12 months post-hatch $(p<0.05)$, suggesting a compensatory growth response.

\section{Reproductive confinement and embryonic development}

Cultured fishes routinely escape from aquaculture facilities. They may pose ecological impacts upon receiving ecosystems, especially if they are a non-native species, and they pose genetic impacts upon populations with which they can interbreed. These concerns are especially pertinent where aquaculture development is intensive and where populations of conservation concern occur in the accessible ecosystem. Further, reproductive confinement protects the interest of the breeder in their investment in a genetic improvement program. Hence, lines of research have been opened into reproductive confinement of several key species groups. In mammals, which have an XX/XY sex determination system, the Sry (sexdetermining region of the $\mathrm{Y}$ chromosome) gene was identified by Sinclair et al. (1990) as the first vertebrate master sex-determining gene. In birds, which have a female heterogametic $(\mathrm{ZZ} / \mathrm{ZW})$ sex-determination system, the Z-linked Dmrt1 (doublesex and mab-3 related transcription factor 1) gene is a strong candidate for the chicken sex-determining gene (Smith et al. 2009), triggering gonadal masculinization by a double dosage mechanism in males. Fishes exhibit a diversity of sex-determination systems (Mank and Avise 2009). Those systems are not well characterized in aquaculture species. Genome-editing techniques have contributed to understanding of sex determination in some species and towards development of reproductively confined aquaculture stocks.

Zhang et al. (2014) employed CRISPR/Cas9 to knock out the $d m r t 6$ gene in Nile tilapia. This knockout resulted in fewer spermatocytes, down-regulated cytochrome $\mathrm{P}_{450}$ family 11 subfamily B member 2 (Cyp11b2) in testes, and consequently produced a lower level of serum 11-ketotestosterone (11-KT) in dmrt6-deficient XY (male) fish compared to the XY control at 120 daysafter-hatch (dah). From 150 to 180 dah, spermatogenesis gradually recovered, and cyp $11 b 2$ expression and serum 11-KT level were restored to the same levels as in the $\mathrm{XY}$ control fish. A dmrt6 mutation was observed in the genomic DNA of sperm of $G_{0}$ mutant and $F_{1}$ fish. Thus, the $d m r t 6$ gene is highly expressed in spermatocytes and is involved in spermatogenesis in tilapia.

Li et al. (2014) used CRISPR/Cas9 to disrupt selected genes involved in sexual differentiation in Nile tilapia, including nanos2, nanos3, dmrt1, and foxl2. Nanos 2 plays a key role in the sexual differentiation of germ cells by promoting the male fate and suppressing the female fate by suppressing meiosis. Nanos 3 maintains the undifferentiated state of germ cells regulating the spermatogonia cell cycle and inducing a prolonged transit in G1 phase. Foxl2, or forkhead box L2, encodes a protein containing a fork-head DNA-binding domain and may play a role in ovarian development and function. Mutation efficiencies as high as $95 \%$ were observed. In the $G_{0}$ generation, loss of Nanos2 and Nanos3 in XY and XX fish resulted in germ cell-deficient gonads. Masculinization of somatic cells in both $\mathrm{XY}$ and $\mathrm{XX}$ gonads was demonstrated by Dmrt1 and Cyp11b2 immunohistochemistry 
and by up-regulation of serum androgen levels. Mutations in dmrt1 and foxl2 induced by CRISPR/Cas9 were efficiently transmitted through the germline to the $F_{1}$ generation.

Steroidogenic factor-1 ( $S f-1)$, also known as nuclear receptor subfamily 5 group A member 1 (NR5A1) is a master regulator of steroidogenesis and reproduction in mammals. Using immunohistochemistry, Xie et al. (2016) detected expression of $S f-1$ in steroidogenic cells, interstitial, granulosa, and theca cells of the ovary, and in Leydig cells of the testis in Nile tilapia. CRISPR/Cas9-mediated cleavage of $s f-1$ resulted in a high mutation rate in the $\mathrm{F}_{0}$ generation associated with gonadal dysgenesis and reduced steroidogenic cells in XX (female) and XY (male) fish. In XX fish, $s f-1$ deficiency also resulted in decreased cytochrome $\mathrm{P}_{450}$ family 19 subfamily $\mathrm{A}$, polypeptide 1a, forkhead box L2, and serum estradiol-17b expression. In XY fish, Sf-1 deficiency increased cytochrome $\mathrm{P}_{450}$ family 19 subfamily A polypeptide $1 \mathrm{a}$ and forkhead box L2 expression, but decreased cytochrome $\mathrm{P}_{450}$ family 11 subfamily B polypeptide 2 expression and serum 11-ketotestosterone levels. 17a-methyltestosterone treatment rescued the gonadal phenotype of $S f$-1-deficient XY fish, leading to normal spermatogenesis and production of $\mathrm{F}_{1}$ mutants. In contrast, estradiol-17 $\beta$ treatment only partially rescued the gonadal phenotype of $S f$-1-deficient $\mathrm{XX}$ fish, as demonstrated by the appearance of phase II oocytes. Further, both $s f-1^{+/-} \mathrm{F}_{1} \mathrm{XX}$ and $\mathrm{XY}$ mutants developed as fertile males, although spermatogenesis was delayed and efferent duct formation was disordered. $S f-1$ deficiency resulted in gonadal dysgenesis and feminization of XY gonads, and also resulted in female-to-male sex reversal in $8.1 \%$ of $\mathrm{F}_{0}$ and $92.1 \%$ of $s f-1^{+/-} \mathrm{F}_{1} \mathrm{XX}$ fish.

Gonadal soma-derived factor (Gsdf) is a TGF- $\beta$ superfamily member expressed only in the gonads of fish, predominantly in the Sertoli cells and neighboring spermatogonia of the testes. There was no direct evidence of transcriptional regulation of $g s d f$. Jiang et al. (2016) used CRSPR/Cas9 to knock out the $g s d f$ gene of Nile tilapia. $\mathrm{F}_{0}$ gsdf-deficient $\mathrm{XY}$ fish with high mutation rate $(>58 \%)$ developed as intersex individuals, exhibiting ovotestes at 90 dah, and became completely sex-reversed with ovaries at 180 and 240 dah. Individuals with low mutation rate $(<58 \%)$ and $\mathrm{XY} g s d f^{+/-}$fish developed as males with normal testes. In $\mathrm{F}_{2} \mathrm{XY} g s d f^{-1-}$ fish, the gonads first expressed Dmrt1 (doublesex and mab-3 related transcription factor 1), which initiated the male pathway at 10 dah; then both male and female pathways were activated, as reflected by the simultaneous expression of Dmrt1 and Cyp19a1a (ovarian aromatase) in different cell populations at $18 \mathrm{dah}$, and then shifted to the female pathway, expressing only Cyp19a1a at 36 dah, and developed functional ovaries as adults. The male pathway and Dmrt1 expression were initiated but not maintained in the absence of Gsdf. Aromatase-inhibitor treatment from 10 to 35 dah rescued the phenotype, resulting in XY gsdf $f^{-1-}$ individuals with normal testes that expressed Dmrt1 and Cyp11b2. In-vitro promoter analyses demonstrated that Dmrt1 activated $g s d f$ expression in a dose-dependent manner in the presence of Sf1, although Dmrt1 alone could not. The results demonstrated that $g s d f$ is a factor downstream of $d m r t 1$ in the reproductive regulatory pathway, probably inhibiting estrogen production to trigger testicular differentiation.

Eukaryotic translation elongation factor $1 \mathrm{~A}(\mathrm{eEF} 1 \mathrm{~A})$ is critical for protein synthesis, as it delivers aminoacylated tRNAs to the A site of the ribosome. Mutation of elongation factors for protein synthesis may result in infertility in vertebrates, but the role of eEF1A remains to be elucidated. CRISPR/Cas9-mediated mutation of $e E F 1 A 1 b$ resulted in arrest of spermatogenesis and infertility in $\mathrm{F}_{0}$ male Nile tilapia (Chen et al. 2017). Heterozygous mutation of $e E F 1 A 1 b$ resulted in absence of spermatocytes at 90 dah, very few spermatocytes, spermatids, and spermatozoa at $180 \mathrm{dah}$, and decreased Cyp11b2 and serum 11-ketotestosterone level at both stages. The $e E F 1 A 1 b+/-$ males proved infertile due to abnormal spermiogenesis. Transcriptomic analyses of the $e E F 1 A 1 b+/-$ testis from fish 180 dah revealed that key elements involved in spermatogenesis, steroidogenesis, and sperm motility were significantly down-regulated compared with the control XY. Hence, $e E F 1 A 1 b$ is crucial for spermatogenesis and male fertility in Nile tilapia.

The urinary and genital systems are closely related during embryogenesis. Wilms tumor 1 (Wt1) is an essential factor for urogenital system development. Teleost fishes have two $w t 1$ genes, $w t 1 a$ and $w t 1 b$. Jiang et al. (2017) studied the expression and functions of wt1a and wt1b on the urogenital system of Nile tilapia using in-situ hybridization and CRISPR/Cas9-mediated gene knockout. wt1a was expressed in the glomerulus of the kidney at 3 dah, earlier than $w t 1 b$. Wt1a and $w t 1 b$ were simultaneously expressed in the somatic cells of gonads at 3 dah, when their cellular localizations were similar, although not so in adult fish gonads. The $w t 1 a^{-1-}$ fish displayed pericardial edema and yolk-sac edema at 3 dah which subsequently expanded to general body edema at 6 dah, failed to develop the glomerulus, and died during 6-10 dah, while the $w t 1 b^{-1-}$ fish were phenotypically normal. Immunohistochemical analyses revealed that the germcell marker Vasa was expressed, while somatic-cell genes Cyp19a1a, Amh, Gsdf and Dmrt1 were not expressed in the $w t 1 a^{-1-}$ gonads at $6 \mathrm{dah}$. The sex phenotypes of XX and $\mathrm{XY}$ in the $w t 1 b^{-/-}$fish were not affected. Real-time PCR showed that ovarian cyp19a1a expression was upregulated in $\mathrm{XX} w t 1 b^{-1-}$ fish relative to $\mathrm{XX}$ control fish at 
90 dah. Serum estradiol-17 $\beta$ level was also up-regulated in XX $w t 1 b^{-1-}$ fish at 90 and 180 dah. The XY $w t 1 b^{-1-}$ fish had normal serum estradiol-17 $\beta$ and 11-ketotestosterone levels and remained fertile. The results show that Wt1a and Wt1b have different functions in the kidneys and gonads of Nile tilapia.

As a first step towards generating sterile channel catfish, Qin et al. (2016) electroporated three sets of zinc finger nuclease plasmids targeting the luteinizing hormone $(L H)$ gene into one-cell embryos. DNA sequencing and mating experiments showed that channel catfish carrying the mutated $L H$ gene were sterile. Carp pituitary extract failed to induce spawning and restoration of fertility, indicating the need for developing other hormone therapies to achieve reversal of sterility upon demand.

Wargelius et al. (2016) investigated whether it is possible to produce germ cell-free Atlantic salmon in the $\mathrm{F}_{0}$ generation by using CRISPR/Cas9 to knock out dead end, or $d n d$, a factor required for the survival of germ cells in vertebrates. To avoid studying mosaic animals, $s l c 45 a 2$, or $a l b$, a pigmentation gene, was targeted simultaneously as an obvious visual tracer, as the phenotype of alb knockout is complete loss of pigmentation. Induced mutations for the alb and the $d n d$ genes were highly correlated and produced germ cell-less fish lacking pigmentation, demonstrating the utility of alb knockout as a tracer for targeted double allelic mutations in $\mathrm{F}_{0}$ animals in species with long generation times. Analysis of gene expression and histology of $d$ nd knockout fish showed that sexual differentiation of the somatic compartment did not depend on the presence of germ cells, although the organization of the ovarian somatic compartment seemed compromised in mutant fish. Kleppe et al. (2017) showed that the germ cell-free Atlantic salmon remained immature and did not undergo puberty (Fig. 4). Salmon lacking germ cells cannot be used for breeding; hence, a strategy for recovering reproductive ability is needed for these fish to prove useful for aquaculture. Guralp et al. (2020) reported a rescue approach for producing germ cells in $d n d$ knockout fish. They co-injected the wild-type variant of salmon dnd mRNA together with CRISPR/ Cas9 constructs targeting $d n d$ into one-cell stage embryos. Rescued one-year-old fish contained germ cells, i.e., type A spermatogonia in males and previtellogenic primary oocytes in females. Further study is needed of germline transmission of $d n d$ mutations and examination of phenotypes and genotypes of $F_{1}$ juveniles. The group is examining the maturation process in rescued males and females, which takes an additional year in females, so that generation of $F_{1}$ homozygous and heterozygous carriers of the mutation would occur in 2021. The generation of sterile offspring will take four more years, but poses production of thousands of sterile larvae. Hence, evaluation of this technology is ongoing and scale-up to commercialization is yet over the horizon.

In vertebrates, female germ cells enter meiosis during embryonic development, while male germ cells enter meiosis at puberty. Retinoic acid (RA) is the key factor controlling the sex-specific timing of meiotic initiation in tetrapods; however, the role of RA in meiotic initiation in teleost fishes has remained unclear. The level of RA is regulated by the balance between synthesis by the retinal dehydrogenase enzymes Aldh1a1-3 and oxidative degradation by the enzymes Cyp26a1, b1, and c1 (cytochrome $\mathrm{P}_{450}$ family 26 subfamily A member 1 , subfamily B member1, and subfamily $C$ member 1 , respectively). The key factors regulating meiotic initiation in germ cells in fish remain unclear. Feng et al. (2015) characterized the genes encoding RA synthase aldh1a2, and catabolic enzyme cyp26a1 of Nile tilapia, a species lacking the gene stra 8 (stimulated by retinoic acid gene 8 ). The expression of aldh1a2 was up-regulated and cyp26a1 was

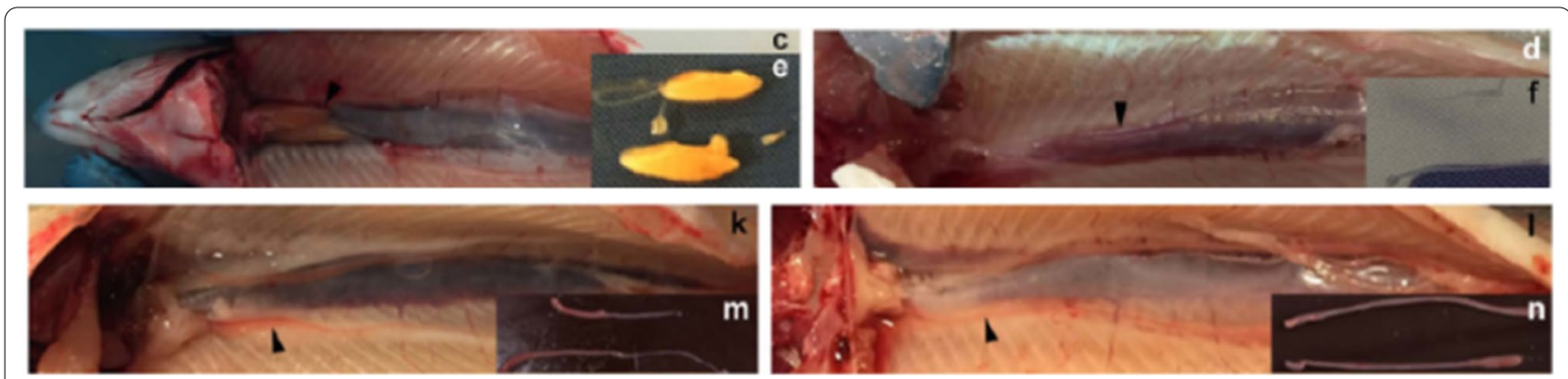

Fig. 4 Aiming to produce reproductively confined Atlantic salmon, Wargelius et al. (2016) knocked out dnd, which encodes a factor required for survival of germ cells. The induced $d n d$ mutations produced fish lacking germ cells. Kleppe et al. (2017) showed that germ cell-free salmon remained immature and did not undergo puberty. Top left: Wild-type female; inset picture shows developed ovaries. Top right: Dnd-knockout female showing no ovarian development. Bottom left: Wild-type male with developed testes. Bottom right: Dnd-knockout male with undeveloped testes 
down-regulated before the meiotic initiation in ovaries and in testes. Treatment with RA synthase inhibitor or disruption of the aldh1a2 gene by CRISPR/Cas9-mediated genome editing resulted in delayed meiotic initiation, with simultaneous down-regulation of cyp26a1 and up-regulation of sycp3 (synaptonemal complex protein $3)$. Treatment with an inhibitor of RA catabolic enzyme and disruption of cyp26a1 resulted in earlier meiotic initiation, with increased expression of aldh1a2 and sycp 3. Treatment of XY male fish with estrogen (E2) and XX fish with fadrozole led to sex reversal and reversion of meiotic initiation. Thus, RA is indispensable for meiotic initiation in teleost fishes via a stra8-independent signaling pathway, and E2 is a major regulator of sex determination and meiotic initiation in teleost fishes.

The stra 8 gene has been observed in several fish species, including Southern catfish Silurus meridionalis. Li et al. (2016a) used immunohistochemistry, real-time PCR, administration of exogenous RA, inhibition of RA degradation, and CRISPR/Cas9-mediated knockdown of cyp26a1 and showed induced meiotic initiation in the ovaries. Hence, RA might trigger meiotic initiation via stra8-dependent and independent pathways in different teleost fishes.

Among 26 species of sturgeon, 22 are in some degree of imperilment. Techniques promoting captive propagation of imperiled species would be valued for conservation aquaculture aimed at demographic enhancement of targeted populations. Use of surrogate species has been demonstrated in several piscine systems, in which germline cells of the species of conservation interest are transplanted into a germ cell-free host of a related species, ultimately yielding gametes. Such an approach would be especially valued because of the late age-at-maturity for sturgeons, but could be complicated by the polyploid genome of the species. Because of its relatively young maturation, Baloch et al. (2019) chose sterlet as the surrogate for producing late-maturing species of sturgeons. Using CRISPR/Cas9 technology to knock out $d n d 1$, few or no primordial germ cells were detected in crispants. Comparing three methods established to achieve sterility in sterlet, they found higher embryo survival and hatching rates using CRISPR/Cas9 than for UV light treatment or morpholino oligonucleotides.

\section{Disease resistance}

Aquaculturists routinely hold their stocks at population densities well above those found in nature, and the organisms may be subject to physiological or social stress, rendering them susceptible to parasites and pathogens. Losses to parasites and disease threaten the viability of aquaculture operations. While informed culturists attend to water quality to minimize that driver of stress and practice biosecurity to limit entry of parasites and pathogens into their facilities, genetic improvement of disease resistance remains a high breeding priority. Several genome-editing experiments have addressed improvement of disease resistance.

Toll-like receptors (TLRs) are integral membrane glycoproteins with leucine-rich repeat (LRR) domains in their extracellular regions for binding pathogen-associated molecular patterns (PAMPs), and a Toll-interleukin-1 receptor domain (TIR), which transmits downstream signals into the cytosol to cue response of the immune system. Elucidation of immune-related pathways has been achieved by establishing model animals with disrupted target genes, often knock-out mice. Chakrapani et al. (2016) used the CRISPR/Cas9 system to disrupt the Tolllike receptor 22 (TLR22) gene of rohu Labeo rohita, a farmed Indian major carp. The null mutant lacked TLR22 mRNA expression. This carp model system could be used to investigate the role pf TLR22 regarding resistance to pathogenic double-stranded RNA viruses, bacteria, and parasites such as fish lice.

The hemorrhagic disease of grass carp Ctenopharyngodon idellus, induced by grass carp reovirus (GCRV), leads to huge economic losses. An effective approach is needed to control against multiple genotypes of GCRV. Junctional adhesion molecule-A (JAM-A) is an immunoglobulin superfamily (IgSF) member. Recent reports suggest that the grass carp JAM-A may be a useful target for developing strategies against GCRV infection. Ma et al. (2018) used CRISPR/Cas9 to knock out the grass carp $J A M-A$ gene and evaluated in vitro resistance against various GCRV genotypes. The results showed that CRISPR/ Cas9 effectively knocked out JAM-A and reduced GCRV infection for two different genotypes in grass carp kidney cells. The results demonstrated that JAM-A is necessary for GCRV infection, suggesting a potential approach for viral control in aquaculture. In-vivo experiments with whole fish will be needed.

Disease resistance is an important trait for commercial channel catfish production, and Elaswad et al. (2018) targeted two disease susceptibility-related genes. The toll/ interleukin 1 receptor domain-containing adapter molecule (TICAM1) gene is involved in the signaling pathway initiated by Toll-like receptor 3 . In channel catfish, TICAM1 was dramatically upregulated following bacterial challenge with Edwardsiella ictaluri, while it was downregulated in blue catfish Ictalurus furcatus, a closely related species resistant to the disease. The rhamnose binding lectin $(R B L)$ gene plays an important role in early infection with Flavobacterium columnare, the causative agent of columnaris disease, where acute and robust upregulation was recorded in a columnaris-susceptible channel catfish strain compared to a columnaris-resistant 
strain. The authors used CRISPR/Cas9 to target those genes. The TICAM1 mutation rate was $79 \%$ in the 24 individuals analyzed; deletion mutations resulted in removal of a few to several amino acids from the predicted TICAM1 protein, changing the downstream reading frame and prematurely terminating translation. The $R B L$ mutation rate was $88 \%$ among 40 individuals analyzed; deletions ranged from 5 to $183 \mathrm{bp}$, while up to $20 \mathrm{bp}$ were inserted. The 183 -bp deletions completely removed intron 1 , exon 2 , and $19 \mathrm{bp}$ from intron 2 , which should influence the splicing of the $R B L$ gene since the splice sites were mutated. Any effects of the mutations on survival and disease resistance were not reported.

One strategy for development of disease-resistant lines would be addition of genes whose products confer resistance to disease. One class of antimicrobial peptides (AMPs) that could prove useful are cathelicidins, which exhibit broad-spectrum antimicrobial activity. Cathelicidins derived from American alligator Alligator mississippiensis exhibit strong activity against some Gram-negative bacteria, as well as multi-drug resistant bacterial pathogens such as Acinetobacter baumannii and Klebsiella pneumoniae. Using CRISPR/Cas 9, Simora et al. (2020) integrated an exogenous alligator cathelicidin gene at high efficiency into a targeted non-coding region of channel catfish chromosome 1 using synthesized linear double-stranded DNA and cloned plasmid DNA constructs. They tested two different promoters for driving expression of the gene, the zebrafish ubiquitin promoter and common carp $\beta$-actin promoter. Integration rates were higher in dead fry than in live fingerlings, indicating either off-target effects or pleiotropic effects. Low levels of mosaicism were detected in the tissues of $\mathrm{P}_{1}$ individuals harboring the transgene, and high transgene expression was observed in the blood of some $\mathrm{P}_{1}$ fish. This may indicate expression of cathelicidin in neutrophils and macrophage granules, as is observed for most antimicrobial peptides. Follow-up studies will be needed to compare expression of cathelicidin driven by the ubiquitin and $\beta$-actin promoters. High expression of cathelicidin in the blood, gills, and other tissues of channel catfish is suggestive of potential disease resistance. Variability in expression among individuals indicate that selection among founders likely will be needed to maximize disease resistance.

\section{Other breeding goals}

Genome editing might be applied to approach other breeding goals as well, including muscle contraction properties, coloration, and fatty acid composition of the flesh.

Aquaculture of tuna is an emerging sector in Mexico, Australia, and Japan, and countries on the Mediterranean
Sea. Producers have observed high mortality rates for hatchery-reared juveniles following panic-induced collisions with the walls of sea cases, often driven by changes in illumination. A mutant zebrafish displaying slow swimming and weak muscle contractions in response to external stimuli carried a 32-bp cDNA insertion in the ryanodine receptor $(r y r 1 b)$ gene, whose product allows the sarcoplasmic reticulum to release $\mathrm{Ca}^{2+}$ in fast skeletal muscle, suggesting that $r y r 1 b$ is critical to high-speed swimming of fish. Higuchi et al. (2019) used TALENS targeting exons 2 and 43 of the Pacific bluefin tuna Thunnus orientalis ryr $1 b$ gene and induced such deletions. Ryr $1 b$ expression was significantly decreased in the mutated $\mathrm{G}_{0}$ larvae at seven dah. A behavioral assay showed that the ryr $1 b$-mutated larvae swam away less efficiently in response to mechanosensory stimulation at 7 dah than did wild-type larvae. The ryr $1 b$-mutated larvae survived to a month after hatch. Further studies are needed to examine the response to sudden illumination of ryrlbmutated fish at the juvenile and later stages. Ryr1bmutated fish will have to be reared to adulthood for the establishment of homozygous null $F_{1}$ fish and to examine survival, growth and fillet quality. Amorphous cores in muscle may affect fillet quality. Further, poor swimming behaviour may negatively impact spawning behaviour and mating success.

Coloration is a trait of interest in some aquaculture species, as novel coloration may attract consumer attention to a fish product in the marketplace. As noted above, by knocking out the tyrosinase (tyr) and solute carrier family 45, member 2 (slc45a2) genes of Atlantic salmon, Edvardsen et al. (2014) observed a graded range of phenotypes ranging from complete lack of pigmentation to partial loss and normal pigmentation. Large-scale loach Paramisgurnus dabryanus is an important aquaculture species in southeast Asia. Traits of breeding interest include body color, and $\mathrm{Xu}$ et al. (2019) employed the CRISPR/Cas9 system to target tyr. Two guide RNAs were designed and used separately, transforming $89.4 \%$ and $96.1 \%$ of injected loach juveniles, respectively, which displayed loss of pigmentation. One group of juveniles, termed clear albino, may have high ornamental and commercial value. White crucian carp (Carassius auratus cuvieri, WCC), a subspecies of goldfish, is economically important in Asia. Liu et al. (2019) used CRISPR-Cas9 to target tyr in WCC and in hybrid progeny (WR) of a cross of female WCC and male red crucian carp (Carassius auratus red variety, RCC). Both the mutant WCC and the mutant WR showed different degrees of melanin reduction compared to wild-type sibling control fish, with mutation efficiencies ranging from 60 to $90 \%$. A profile of gene expression for pigment synthesis genes tyrp1, mitfa, mitfb, dct and sox10 showed down-regulation in 
the tyr-edited WCC, which caused the observed reduction in melanin synthesis.

The health benefits of fish oil, particularly eicosapentaenoic acid (20:5n-3) and docosahexaenoic acid (22:6n3 ), are well documented for prevention of inflammatory and cardiovascular diseases in humans. Products of coldwater marine fishes are the primary dietary sources of omega-3 long chain polyunsaturated fatty acids ( $n-3$ LC-PUFAs) in the human diet. Cultured fishes tend to have lower levels of n-3 LC-PUFAs than wild fish, especially fish fed diets in which vegetable oils have been substituted for fish oil and meal, supplies of which are increasingly limited. To a limited degree, Atlantic salmon can synthesize polyunsaturated fatty acids (PUFAs), such as eicosapentaenoic acid, arachidonic acid (20:4n6) and docosahexaenoic acid via activities of very long chain fatty acyl elongases (Elovls) and fatty acyl desaturases (Fads). Understanding the molecular mechanisms of PUFA biosynthesis and regulation would be valued. Datsomor et al. (2019) used CRISPR/Cas9 to partially knock out the elovl2 gene and showed that the enzyme is crucial for multi-tissue synthesis of 22:6n-3 in vivo and that endogenously synthesized PUFAs are important for transcriptional regulation of lipogenic genes. The elovl2knockout fish showed reduced levels of 22:6n-3 and accumulation of 20:5n-3 and docosapentaenoic acid (22:5n-3) in liver, brain and white muscle, suggesting inhibition of elongation. Additionally, elovl2-knockout salmon showed accumulation of 20:4n-6 in brain and white muscle. The impaired synthesis of 22:6n-3 induced hepatic expression of sterol regulatory element binding protein-1 (srebp-1), fatty acid synthase-b, $\Delta 6 f a d-a, \Delta 5 f a d$ and elovl5. Thus, thus study demonstrated key roles of elovl2 at the two penultimate steps of PUFA synthesis in vivo and suggested that Srebp-1 is a main regulator of endogenous PUFA synthesis in Atlantic salmon.

\section{Other aquaculture species}

The scope of world aquaculture is broader than fishes, and includes mollusks, crustaceans, and seaweeds (FAO 2020). Recent work has developed protocols for genome editing of members of these taxa.

$\mathrm{Yu}$ et al. (2019) investigated the possibility of delivering CRISPR/Cas9 ribonucleoproteins into Pacific oyster Crassostrea gigas eggs by microinjection and sought to optimize doses of sgRNA and Cas9 for inducing mutations in the targeted myostatin and Twist (a transcription factor) genes. Their results showed indel mutations of 1-24 bp, demonstrating the utility of the approach for marine mollusks. Li et al. (2021) applied CRISPR/Cas9 technology to analyze the function of myosin essential light chain $(C g M E L C)$ during larval development of $C$. gigas. The approach caused extensive indel mutations in the CgMELC gene, and mutant larvae showed defective musculature and reduced motility. Potts et al. (2021) asserted that genome editing is achievable on a greater scale in mollusks that in other farmed taxa, making genome-wide CRISPR-based screening approaches plausible, and discussed the potential of selective breeding, genomic approaches, and genome editing for understanding and improving resistance to infectious disease in mollusks.

Among aquaculture species, crustaceans are difficult to transform, as fertilization is internal. While protocols have been developed for microinjection of spermatophores or ovary and for ballistic introduction of gene constructs into embryos, low frequency of transformation, and random genomic integration discouraged use of classical gene transfer techniques. Recent work with oriental or ridgetail white prawn Exopalaemon carnicaudata has shown how genome editing of crustaceans may be practiced. Gui et al. (2016) applied CRISPR/Cas9 technology, co-injecting mRNA of Cas9 nuclease and gRNA targeted for the E. carinicauda chitinase 4 (EcChi4) gene. Shrimps with indel mutations were obtained, the first site-specific genome editing of a decapod crustacean. The mutations were transmitted to the next generation. Xu et al. (2020) reviewed embryonic microinjection techniques for three model crustaceans-(the cladocerans Daphnia magna and D. pulex, amphipod Parhyale hawaiensis, and decapod E. carinicauda) and described two potentially useful new techniques for delivering CRISPR/Cas9 components into crustaceans, Receptor-Mediated Ovary Transduction of Cargo (ReMOT Control) and electroporation. Experience with genome editing of these model species can inform genome editing of cultured species.

Production of seaweeds is the largest sector of world aquaculture (FAO 2020). Despite a search of the technical literature, I found no reports of genome editing of seaweeds.

\section{Towards practical adoption of genome-edited fishes}

Because their life history is amenable to genetic manipulation and their importance to aquaculture, much effort has been devoted to genetic modification of fishes (Hallerman 2021). The first two genetically modified animal products marketed to consumers are fishes. GloFish are fluorescent aquarium fishes of several species now marketed in the United States and Canada (www.glofi sh.com). The AquAdvantage salmon (www.aquabounty. com) is a rapidly growing Atlantic salmon, marketed in Canada and in the United States, and perhaps soon in Brazil. However, these products result from applications of classical gene transfer techniques. New genomeediting techniques yield higher transformation rates and 
better target a modification to a specific genomic site. What, then, are the prospects for commercial production of genome-edited fishes? Rising world aquaculture production poses great potential for commercial application. What will it take for this potential to be realized? The body of studies cited above suggest that we are well on our way to having the techniques needed for purposeful genome editing of aquaculture species. While technology is necessary, it is not, however, sufficient. The experience with animals modified using classical gene transfer techniques shows the need for progress in key non-technical areas.

\section{Regulatory context}

Underlying any regulatory policy are the definitions of regulated articles, which thereby define the scope of regulation. Technical definitions underlying existing biotechnology regulatory policies may need to be updated to encompass new breeding technologies, such as genome editing. As noted above, SDN-1 and SDN-2 can introduce base-pair changes or small insertions or deletions without addition of foreign DNA; the exact change cannot be predetermined and is quasi-random at the target site. SDN-2 uses a small DNA template to generate a specific change by homologous recombination. SDN-3 inserts larger DNA elements of foreign origin using an approach similar to SDN-2. The distinction between these SDN categories in public policy may affect government oversight of animals produced by genome-editing technology (e.g., European Commission/SWD 2021) and likely also public perception of applications of genome editing (Friedrichs et al. 2019; Hallerman et al. in press). As noted below, SDN-1-edited animals may not be regulated as GMOs in some countries.

Different approaches to definition of new breeding technologies and oversight of food safety of associated products have been adopted in different countries and groups of countries, and varying levels of progress have been achieved (Schmidt et al. 2020; Okoli et al. 2021; Hallerman et al. in press; Fig. 5). In Europe, the EU Court of Justice (ECJ) ruled in 2018 that all genomeedited organisms must be categorized as GMOs and thus are subject to significant regulatory burdens under the EU GMO Directive (Schmidt et al. 2020; Okoli et al.

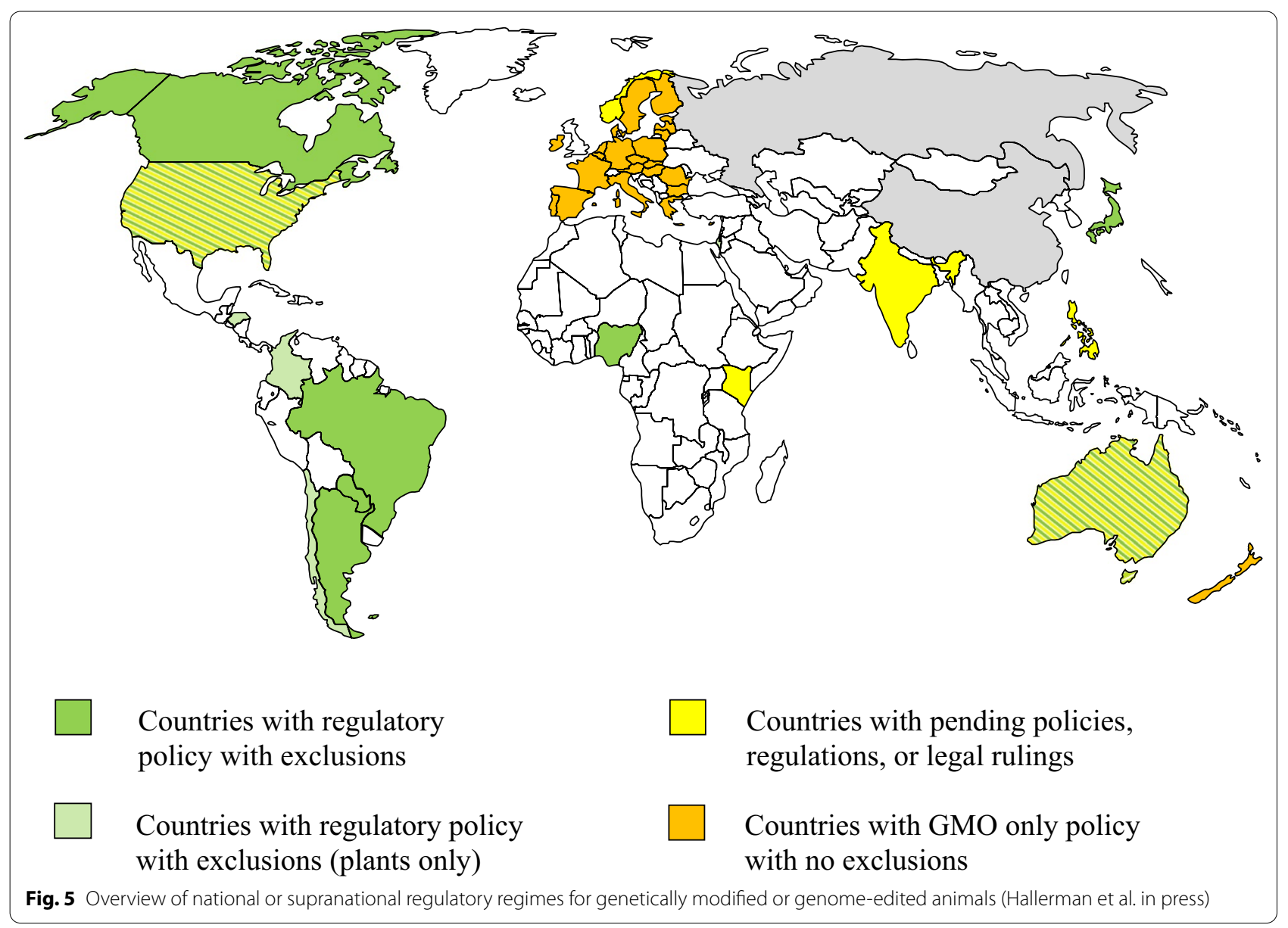


2021). New Zealand regulates genome editing under its GM biosafety rules, also following a court decision. In January 2020, India released a draft document on genome-edited organisms, "Regulatory Framework and Guidelines for Risk Assessment", which proposes a tiered approach to group products based on risk, with single or a few base-pair edits identified as low risk, and insertion of large or foreign DNA as higher risk; India recently requested public comments to inform their decisions on future policies on genome editing, and the document is under revision. Although China has most publications and patents for genome-editing applications in agriculture (Cohen 2019; Martin-Laffon et al. 2019), they do not yet have a regulatory framework for evaluating genome-edited products distinct from that for GM products; proponents must obtain both a safety certificate and a business-related certification before commercialization can go forward, which has proven a road block for commercialization of GM crops (Li et al. 2016b, 2020). The degree of oversight to be applied to genome-edited organisms hopefully will be scaled to any food or ecological risk posed that organism, noting that ecological risk can be managed by appropriate risk management (Kapuscinski et al. 2007). Risk assessment frameworks and guidelines specific to organisms and products developed by genome-editing technologies including CRISPR/Cas do not yet exist; risk assessors currently adopt frameworks originally developed for classical GMOs (Agapito-Tenfen et al. 2018). Experience and guidance specific for risk assessment of genome-edited fish do not yet exist (CBD/SBSTTA 2020; Sweet 2019). This background led Okoli et al. (2021) to regard current regulatory and risk assessment frameworks as not fit-for-purpose.

Japan is a Party to the Cartagena Protocol, promulgated following the adoption of the Convention on Biological Diversity, that obligates Parties to establish the means to regulate the use and release of living modified organisms (LMOs). After considering organisms produced by genome editing, the Japanese government determined that some genome-edited organisms should be considered as LMOs, while others are not subject to the Japan's Cartagena Act (Tsuda et al. 2019). Genome-edited end products derived by modifications of SDN-1 typedirected mutation without using a DNA sequence template-would not represent LMOs under the Japanese Cartagena Act. Hence, in 2021, the Japanese Ministry of Health, Labor and Welfare (MHLW) determined that two genome-edited fishes with increased edible muscle, myostatin knockouts in red sea bream Pagrus major and tiger puffer Takifugu rubripe, are not GM and therefore are not subject to a requisite GM food safety review (MHLW 2021).
The genome-edited Nile tilapia FLT-01 developed by AquaBounty (then part of Intrexon) was created using microinjection with nuclease mRNA, without introduction of DNA. The final product is homozygous for the 26-bp deletion, and no off-target sites of modification were observed. Critical in regulatory consideration of the FLT-01 fish is lack of new genetic material or unwanted integration of plasmid DNA in the final product. In particular, it does not contain a new combination of genetic material in the genome generated by the application of modern biotechnology, and hence is not covered by the definition of a regulated article under Res. 763 under the Cartagena Protocol for Biosafety (https://bch.cbd.int/ protocol/). Hence, under Argentine Resolution 173/15New Breeding Techniques, this fish is not regarded as a GMO. Brazil made a similar determination for this genome-edited fish in 2019.

Regulatory frameworks have tended to focus upon the food and environmental safety of products of biotechnology, and generally have not addressed non-safety issues in an attempt to reach a decision that is socially acceptable (Myskja and Myhr 2020). Several countries, however, have implemented such measures. In Norway, environmental, societal and economic dimensions, as well as non-safety criteria-contribution to sustainable development, ethical justifiability and societal utility-are considered in the evaluation of GMOs.

\section{Commercial context}

Three genome-edited lines of fish are advancing along the pathway towards commercial production. A Kyoto-based start-up, Regional Fish Institute, Ltd., submitted the notifications to the Ministry of Health, Labor and Welfare and the Ministry of Agriculture, Forestry and Fisheries to market these fish, which were the result of a collaboration between Kyoto and Kindai Universities (The Fish Site 2021; Asahi Shimbun 2021; Yomiuri Shimbun 2021). Another product has been submitted to regulatory review, the FLT-01 Nile tilapia, was developed by AquaBounty, the company that developed and produces the transgenic AquAdvantage salmon. Still, some of the species most important to world aquaculture (Table 1) have not yet been subject to genome-editing research, which limits the near-term potential impact of the set of tools.

\section{Consumer acceptance}

The regulatory process and commercialization of crop plants and animals modified by classical gene transfer techniques were complicated by lack of consumer acceptance. Should the respective regulatory authorities come to regard the products of genome editing as not-GMO, especially SDN-1 modifications where the product is essentially no different from those of selective 
breeding, then the mainstream public will accept regulatory assurance that the product is safe. Consumer acceptance may not prove a substantive barrier to commercialization of such genome-edited animal products. However, other genome-editing applications add DNA sequences or modify target sequences in ways that could not be achieved by crosses within species. To promote consumer acceptance, the proponent of a particular product will have to communicate to the public not so much how, but rather why genome-editing technology was applied (Hallerman et al. in press). Such communication will have to speak to the values system of that public, i.e., that application of the technology is safe, produces healthful food, increases animal welfare, or makes production more sustainable. Ultimately, acceptance in the marketplace will depend upon the consumer not only seeing resonance with their values, but also value in the product itself. A wide range of potential consumers will accept products from genome-edited animals with heightened disease resistance, heightened welfare, or product quality (Van Eenennaam 2021). Indeed, results of recent surveys (Conroy 2021) showed that although consumer awareness of genome-editing technology remains low, western consumers have a generally positive view of genome-edited foods, especially if they bring social, economic, and environmental benefits. Consumers were more accepting of genome-edited plants than animals. Younger, more educated, and male respondents were more accepting of the technology.

Market acceptance of GM and GnEd products also can prove critical. After a history of chefs and supermarkets stating that they would not accept the AquaBounty salmon, the company has marketed its product as environmentally conscious and proving rural employment, and sales are now constrained by production capacity.

\section{Development of required technical infrastructure}

Production of genetically improved farmed types can contribute to regional economies and human well-being (ADB 2005). However, only 10\% of world aquaculture production comes from well-managed selective breeding programs (Gjedrem et al. 2012; Oleson et al. 2015), and FAO (2019) reported that most farmed types are considered 'wild type. The adoption of selectively bred stocks varies among species; all Atlantic salmon culture involves selectively bred lines, but virtually none of Chinese and Indian major carp production, which collectively contributes $48 \%$ of world aquaculture production (Table 1), is genetically improved. Development of the infrastructure for selective breeding and distribution of genetically improved lines is a major challenge facing key sectors of world aquaculture (Hallerman et al. 2021). Against this background, it becomes clear that not all sectors are ready today for adoption of genome-edited lines of fishes. Depending upon regulatory and consumer acceptance, I anticipate adoption of genome-edited lines in the salmonid sector, and the recirculating aquaculture segment of the tilapia sector, with other possibilities realized elsewhere only later.

\section{Concluding perspectives}

The studies reviewed here collectively have considerable impact on development of basic knowledge, particularly on understanding of the processes of germ cell and gonadal differentiation and maturation. Regulation of growth is a relatively straightforward and well-studied process, and commercial applications may be seen relatively soon. As noted above, the myostatin-knockout FLT01 line of Nile tilapia shows heightened production, has a proponent in the private sector, and may be approved for production in two countries. Marketing of the first genome-edited animal product as food will be an important development in terms of showing a pathway to commercialization and attracting investment in development of new genome-edited animal lines.

The progress of genome-edited fishes, as all genomeedited animals, to routine production will turn on the policy determination of just what is a regulated article within national biotechnology policy. I anticipate that SDN1 animals will pose little, SDN2 animals moderate, and SDN3 animals with addition of new genetic material a higher level of regulatory concern. However, I expect less popular pushback against genome-edited products that we witnessed for genetically modified products developed using classical gene transfer techniques. This is because genome editing offers better targeting to particular genomic sites, with fewer off-target mutations, and fewer associated animal welfare problems.

While I report progress on applying genome editing to 18 species of fishes, Table 1 shows that these tools are yet to be applied to eight of the 16 most important aquaculture species. This observation suggests that the impact of genome editing upon world aquaculture production will be limited through at least the medium term as new genetic lines are developed, countries develop regulatory oversight policies, and companies adopt lines for production in countries where aquaculture is important to human well-being, particularly in Asia. Much of the work applying genome editing to aquaculture species has occurred in China. This is not surprising, as $\sim 60 \%$ of world aquaculture production occurs in China (FAO 2020) and China has invested heavily in animal biotechnology. This raises the question of whether Chinese regulatory authorities will approve production of genome-edited fishes and animals more generally. 


\section{Acknowledgements}

I thank Editor Peter Hansen for challenging me to do this review.

\section{Authors' contributions}

The author read and approved the final manuscript.

\section{Funding}

My research in this area has been supported by the U.S. Department of Agriculture Foreign Agricultural Service.

\section{Availability of data and materials \\ Not applicable.}

\section{Declarations}

\section{Ethics approval and consent to participate}

Not applicable.

\section{Consent for publication}

Not applicable.

\section{Competing interests}

I declare that I have no competing interests.

Received: 15 September 2021 Accepted: 7 December 2021

Published online: 17 December 2021

\section{References}

ADB (Asian Development Bank). An impact evaluation of the development of genetically improved farmed Tilapia and their dissemination in selected countries. Publication Stock No. 051005. Operations Evaluation Department Asian Development Bank, Manila, Philippines. 2005. https://www. adb.org/sites/default/files/evaluation-document/35050/files/ies-tilap ia-dissemination-0.pdf.

Agapito-Tenfen SZ, Okoli AS, Bernstein MJ, Wikmark OG, Myhr Al. Revisiting risk governance of GM plants: the need to consider new and emerging gene-editing techniques. Front Plant Sci. 2018;9:1874.

Anzalone AV, Randolph PB, Davis JR, Sousa AA, Koblan LW, Levy JM, Chen PJ, Wilson C, Newby GA, Raguram A, Liu DR. Search-and-replace genome editing without double-strand breaks or donor DNA. Nature. 2019;576:149-57.

Asahi Shimbun. Fleshier sea bream due to genome editing hits the market. 2021. https://www.asahi.com/ajw/articles/14445610. Accessed 24 Nov 2021.

Baloch AR, Franěk R, Tichopád T, Fučíková M, Rodina M, Pšenička M. Dnd1 knockout in sturgeons by CRISPR/Cas9 generates germ cell free host for surrogate production. Animals. 2019;9:174.

Barman HK, Rasal KD, Chakrapani V, Ninawe AS, Vengayil DT, Asrafuzzaman S, Sundaray JK, Jayasankar P. Gene editing tools: state-of-the-art and the road ahead for the model and non-model fishes. Transgenic Res, 2017:26:577-89.

Bibikova M, Golic M, Golic KG, Carroll D. Targeted chromosomal cleavage and mutagenesis in Drosophila using zinc-finger nucleases. Genetics. 2002;161:1169-75.

Bibikova M, Beumer K, Trautman JK, Carroll D. Enhancing gene targeting with designed zinc finger nucleases. Science. 2003;300:764.

Blix TB, Dalmo RA, Wargelius A, Myhr Al. Genome editing on finfish: current status and implications for sustainability. Rev Aquac. 2021. https://doi. org/10.1111/raq.12571.

Boch J, Bonas U. Xanthomonas AvrBs3 family-type III effectors: discovery and function. Annu Rev Phytopathol. 2010;48:419-36.

CBD/SBSTTA. Risk assessment and risk management convention on biological diversity/subsidiary body on scientific, technical and technological advice. Twenty-fourth meeting, Quebec City, Canada, 2-7 November 2020. 2020. https://www.cbd.int/doc/c/32ef/df6b/c08d3610ae1 bb8e 7b12d9944/sbstta-24-05-en.pdf. Accessed 5 Dec 2021.
Chakrapani V, Patra SK, Panda RP, Rasal KD, Jayasankar P, Barman HK. Establishing targeted carp TLR22 gene disruption via homologous recombination using CRISPR/Cas9. Dev Comp Immunol. 2016;61:242-7.

Chen J, Jiang D, Tan D, Fan Z, Wei Y, Li M, Wang D. Heterozygous mutation of eEFTA1b resulted in spermatogenesis arrest and infertility in male tilapia, Oreochromis niloticus. Sci Rep. 2017;7:1-5.

Chen J, Wang W, Tian Z, Dong Y, Dong T, Zhu H, Zhu Z, Hu H, Hu W. Efficient gene transfer and gene editing in sterlet (Acipenser ruthenus). Front Genet. 2018;9:117.

Cleveland BM, Yamaguchi G, Radler LM, Shimizu M. Editing the duplicated insulin-like growth factor binding protein-2b gene in rainbow trout (Oncorhynchus mykiss). Sci Rep. 2018;8:16054.

Cohen J. With its CRISPR revolution, China becomes a world leader in genome editing. Science. 2019;365(6452):420-1.

Conrow J. Western consumers have positive attitudes toward gene-edited foods, two new studies find. Alliance for Science, 5 August 2021. 2021. https://allianceforscience.cornell.edu/blog/2021/08/western-consu mers-have-positive-attitudes-toward-gene-edited-foods-two-newstudies-find/. Accessed 26 Nov 2021.

Datsomor AK, Zic N, Li K, Olsen RE, Jin Y, Vik JO, Edvardsen RB, Grammes F, Wargelius A, Winge P. CRISPR/Cas9-mediated ablation of elovl2 in Atlantic salmon (Salmo salar L.) inhibits elongation of polyunsaturated fatty acids and induces Srebp-1 and target genes. Sci Rep. 2019;9:7533.

Donaldson LR, Olson PR. Development of rainbow trout brood stock by selective breeding. Trans Am Fish Soc. 1957;85:93-101.

Dong Z, Ge J, Li K, Xu Z, Liang D, Li J, Li J, Jia W, Li Y, Dong X, Cao S. Heritable targeted inactivation of myostatin gene in yellow catfish (Pelteobagrus fulvidraco) using engineered zinc finger nucleases. PLOS ONE. 2011;6: e28897.

Dong Z, Ge J, Xu Z, Dong X, Cao S, Pan J, Zhao Q. Generation of myostatin B knockout yellow catfish (Tachysurus fulvidraco) using transcription activator-like effector nucleases. Zebrafish. 2014;11:265-74.

Doudna JA, Charpentier E. The new frontier of genome engineering with CRISPR-Cas9. Science. 2014;346(6213):1258096.

Doyon Y, McCammon JM, Miller JC, Faraji F, Ngo C, Katibah GE, Amora R, Hocking TD, Zhang L, Rebar EJ, Gregory PD. Heritable targeted gene disruption in zebrafish using designed zinc-finger nucleases. Nat Biotechnol. 2008;26:702-8.

Dunham RA. Aquaculture and fisheries biotechnology: genetic approaches. 2nd ed. Wallingford: CABI; 2011.

Edvardsen RB, Leininger S, Kleppe L, Skaftnesmo KO, Wargelius A. Targeted mutagenesis in Atlantic salmon (Salmo salar L.) using the CRISPR/Cas9 system induces complete knockout individuals in the $\mathrm{F}_{0}$ generation. PLOS ONE. 2014;9: e108622.

Elaswad A, Khalil K, Ye Z, Liu Z, Liu S, Peatman E, Odin R, Vo K, Drescher D, Gosh K, Qin G. Effects of CRISPR/Cas9 dosage on TICAM1 and RBL gene mutation rate, embryonic development, hatchability and fry survival in channel catfish. Sci Rep. 2018;8:16499.

European Commission/SWD. Study on the status of new genomic techniques under Union law and in light of the Court of Justice ruling in Case C-528/16. 2021. https://ec.europa.eu/competition/international/overv iew/impact_assessment_report.pdf.

FAO (Food and Agriculture Organization of the United Nations). The state of the world's aquatic genetic resources for food and agriculture. FAO Commission on Genetic Resources for Food and Agriculture assessments. Rome; 2019.

FAO (Food and Agriculture Organization of the United Nations). The state of world fisheries and aquaculture 2020: sustainability in action. Rome: FAO; 2020. https://doi.org/10.4060/ca9229en.

Feng R, Fang L, Cheng Y, He X, Jiang W, Dong R, Shi H, Jiang D, Sun L, Wang D. Retinoic acid homeostasis through aldh 1 a2 and cyp26a1 mediates meiotic entry in Nile tilapia (Oreochromis niloticus). Sci Rep. 2015;5:1-12.

Friedrichs S, Takasu Y, Kearns P, Dagallier B, Oshima R, Schofield J, Moreddu C. An overview of regulatory approaches to genome editing in agriculture. Biotechnol Res Innov. 2019;3:208-20.

Garneau JE, Dupuis ME, Villion M, Romero DA, Barrangou R, Boyaval P, Fremaux C, Horvath P, Magadán AH, Moineau S. The CRISPR/Cas bacterial immune system cleaves bacteriophage and plasmid DNA. Nature. 2010;468:67-71. 
Gaudelli NM, Komor AC, Rees HA, Packer MS, Badran AH, Bryson DI, Liu DR. Programmable base editing of A-T to G-C in genomic DNA without DNA cleavage. Nature. 2017;551:464-4671.

Gjedrem T, Robinson N, Rye M. The importance of selective breeding in aquaculture to meet future demands for animal protein: a review. Aquaculture. 2012;350-353:117-29.

Gratacap RL, Wargelius A, Edvardsen RB, Houston RD. Potential of genome editing to improve aquaculture breeding and production. Trends Genet. 2019:35:672-84.

Grobet L, Poncelet D, Royo L, Brouwers B, Pirottin D, Michaux C, Ménissier F, Zanotti M, Dunner S, Georges M. Molecular definition of an allelic series of mutations disrupting the myostatin function and causing doublemuscling in cattle. Mamm Genome. 1998;9:210-3.

Gui T, Zhang J, Song F, Sun Y, Xie S, Yu K, Xiang J. CRISPR/Cas9-mediated genome editing and mutagenesis of EcChi4 in Exopalaemon carinicauda. G3 Genes Genomes Genet. 2016;6:3757-64.

Güralp H, Skaftnesmo KO, Kjærner-Semb E, Straume AH, Kleppe L, Schulz RW, Edvardsen RB, Wargelius A. Rescue of germ cells in dnd crispant embryos opens the possibility to produce inherited sterility in Atlantic salmon. Sci Rep. 2020;10(1):1-2.

Hallerman E. Transgenic fishes: applications, state of the art, and risk concerns. In: Meyers RA, editor. Encyclopedia of sustainability science and technology. New Delhi: Springer; 2021.

Hallerman E, Hilsdorf AWS, Bartley D, Mair G. Toward addressing the limited uptake of genetically improved strains in aquaculture. Rev Aquac. 2021. https://doi.org/10.1111/raq.12561.

Hallerman EM, Bredlau J, Camargo LS, Dagli MLZ, Karembu M, Ngure G, Romero-Aldemita R, Rocha P, Tizard M, Walton M, Wray-Cahen D. Towards progressive regulatory approaches for agricultural applications of animal biotechnology. Transgene Res. (In press).

Higuchi K, Kazeto Y, Ozaki Y, Yamaguchi T, Shimada Y, Ina Y, Soma S, Sakakura Y, Goto R, Matsubara T, Nishiki I, Iwasaki Y, Yasuike M, Nakamura Y, Matsuura A, Masuma S, Sakuma T, Yamamoto T, Masaoka T, Kobayashi T, Fujiwara A, Gen K. Targeted mutagenesis of the ryanodine receptor by Platinum TALENs causes slow swimming behaviour in Pacific bluefin tuna (Thunnus orientalis). Sci Rep. 2019:9:13871.

Horvath P, Barrangou R. CRISPR/Cas, the immune system of bacteria and archaea. Science. 2010;327:167-70.

Huang P, Xiao A, Zhou M, Zhu Z, Lin S, Zhang B. Heritable gene targeting in zebrafish using customized TALENs. Nat Biotechnol. 2011;29:699-700.

Hwang WY, Fu Y, Reyon D, Maeder ML, Tsai SQ, Sander JD, Peterson RT, Yeh $\mathrm{J}$, Joung JK. Efficient genome editing in zebrafish using a CRISPR-Cas system. Nat Biotechnol. 2013;31:227-9.

Jao LE, Wente SR, Chen W. Efficient multiplex biallelic zebrafish genome editing using a CRISPR nuclease system. Proc Natl Acad Sci USA. 2013:110:13904-9.

Jiang DN, Yang HH, Li MH, Shi HJ, Zhang XB, Wang DS. Gsdf is a downstream gene of $d m r t 1$ that functions in the male sex determination pathway of the Nile tilapia. Mol Reprod Dev. 2016;83:497-508.

Jiang D, Chen J, Fan Z, Tan D, Zhao J, Shi H, Liu Z, Tao W, Li M, Wang D. CRISPR/ Cas9-induced disruption of wt $1 a$ and $w t 1 b$ reveals their different roles in kidney and gonad development in Nile tilapia. Dev Biol. 2017:428:63-73.

Kapuscinski AR, Hayes KR, Li S, Dana G, Hallerman EM, Schei PJ. Environmental risk assessment of genetically modified organisms vol. 3: methodologies for transgenic fish. Wallingford: CABI; 2007.

Khalil K, Elayat M, Khalifa E, Daghash S, Elaswad A, Miller M, Abdelrahman H, Ye Z, Odin R, Drescher D, Vo K. Generation of myostatin gene-edited channel catfish (Ictalurus punctatus) via zygote injection of CRISPR/Cas9 system. Sci Rep. 2017;7:7301.

Kim J, Cho JY, Kim J-W, Kim H-C, Noh JK, Kim Y-O, Hwang H-K, Kim W-J, Yeo S-Y, An CM, Park JY, Kong HJ. CRISPR/Cas9-mediated myostatin disruption enhances muscle mass in the olive flounder Paralichthys olivaceus. Aquaculture. 2019;512: 734336.

Kishimoto K, Washio Y, Yoshiura Y, Toyoda A, Ueno T, Fukuyama H, Kato K, Kinoshita M. Production of a breed of red sea bream Pagrus major with an increase of skeletal muscle mass and reduced body length by genome editing with CRISPR/Cas9. Aquaculture. 2018;495:415-27.
Kishimoto K, Washio Y, Murakami Y, Katayama T, Kuroyanagi M, Kato K, Yoshiura Y, Kinoshita M. An effective microinjection method for genome editing of marine aquaculture fish: tiger pufferfish Takifugu rubripes and red sea bream Pagrus major. Fish Sci. 2019;85:217-26.

Kleppe L, Andersson E, Skaftnesmo KO, Edvardsen RB, Fjelldal PG, Norberg B, Bogerd J, Schulz RW, Wargelius A. Sex steroid production associated with puberty is absent in germ cell-free salmon. Sci Rep. 2017;7:12584.

Komor AC, Kim YB, Packer MS, Zuris JA, Liu DR. Programmable editing of a target base in genomic DNA without double-stranded DNA cleavage. Nature. 2016;533:420-4

Kosicki M, Tomberg K, Bradley A. Repair of double-strand breaks induced by CRISPR-Cas9 leads to large deletions and complex rearrangements. Nat Biotechnol. 2018:36:765-71.

Li M, Yang H, Zhao J, Fang L, Shi H, Li M, Sun Y, Zhang X, Jiang D, Zhou L, Wang D. Efficient and heritable gene targeting in tilapia by CRISPR/Cas9. Genetics. 2014;197:591-9.

Li M, Feng R, Ma H, Dong R, Liu Z, Jiang W, Tao W, Wang D. Retinoic acid triggers meiosis initiation via stra8-dependent pathway in Southern catfish, Silurus meridionalis. Gen Comp Endocrinol. 2016a;232:191-8.

Li Y, Hallerman EM, Liu Q, Wu K, Peng Y. The development and status of Bt rice in China. Plant Biotechnol J. 2016b;14:839-48.

Li Y, Hallerman EM, Peng Y. Excessive Chinese concerns over genetically engineered food safety are unjustified. Nat Plants. 2020;6:590.

Li H, Yu H, Du S, Li Q. CRISPR/Cas9-mediated high efficiency knockout of myosin essential light chain gene in the Pacific oyster (Crassostrea gigas). Mar Biotechnol. 2021;23:215-24.

Liu Q, Qi Y, Liang Q, Song J, Liu J, Li W, Shu Y, Tao M, Zhang C, Qin Q, Wang $J$. Targeted disruption of tyrosinase causes melanin reduction in Carassius auratus cuvieri and its hybrid progeny. Sci China Life Sci. 2019;62:1194-202.

Lu J, Fang W, Huang J, Li S. The application of genome editing technology in fish. Mar Life Sci Technol. 2021;3:326-46.

Ma J, Fan Y, Zhou Y, Liu W, Jiang N, Zhang J, Zeng L. Efficient resistance to grass carp reovirus infection in JAM-A knockout cells using CRISPR/Cas9. Fish Shellfish Immunol. 2018;76:206-15.

Maggio I, Goncalves MA. Genome editing at the crossroads of delivery, specificity, and fidelity. Trends Biotechnol. 2015;33:280-91.

Mair GC, Lucente D. What are "farmed types" in aquaculture and why do they matter? FAO Aquac Newsl. 2020;61:40-2.

Mank JE, Avise JC. Evolutionary diversity and turn-over of sex-determination in teleost fishes. Sex Dev. 2009;3:60-7.

Martin-Laffon J, Kuntz M, Ricroch AE. Worldwide CRISPR patent landscape shows strong geographical biases. Nat Biotechnol. 2019;37:613-20.

McPherron AC, Lawler AM, Lee S-J. Regulation of skeletal muscle mass in mice by a new TGF- $\beta$ superfamily member. Nature. 1997;387:83-90.

Meng X, Noyes MB, Zhu LJ, Lawson ND, Wolfe SA. Targeted gene inactivation in zebrafish using engineered zinc-finger nucleases. Nat Biotechnol. 2008;26:695-701.

MHLW (Ministry of Health, Labor and Welfare, Japan). List of foods and additives notified based on the food hygiene handling guidelines for foods and additives that apply genome editing technology. 2021. https:// www.mhlw.go.jp/stf/seisakunitsuite/bunya/kenkou_iryou/shoku hin/bio/genomed/newpage_00010.html. Accessed 8 Nov 2021. (in Japanese).

Myskja BK, Myhr Al. Non-safety assessments of genome-edited organisms: should they be included in regulation? Sci Eng Ethics. 2020;26:2601-27.

NBT Platform. SDN: site-directed nuclease technology. 2014. https://www. nbtplatform.org/background-documents/factsheets/factsheet-sitedirected-nucleases.pdf. Accessed 29 June 2021.

Ohama M, Washio Y, Kishimoto K, Kinoshita M, Kato K. Growth performance of myostatin knockout red sea bream Pagrus major juveniles produced by genome editing with CRISPR/Cas9. Aquaculture. 2020;529: 735672.

Okoli AS, Blix T, Myhr Al, Xu W, Xu X. Sustainable use of CRISPR/Cas in fish aquaculture: the biosafety perspective. Transgenic Res. 2021. https://doi.org/ 10.1007/s11248-021-00274-7.

Olesen I, Bentsen HB, Phillips M, Ponzoni RW. Can the global adoption of genetically improved farmed fish increase beyond 10\%, and how? J Mar Sci Eng. 2015;3:240-66. 
Ponzoni RW, Nguyen NH, Khaw HL, Hamzah A, Bakar KRA, Yee HY. Genetic improvement of Nile tilapia (Oreochromis niloticus) with special reference to the work conducted by the Worldfish Center with the GIFT strain. Rev Aquac. 2011;3:27-41.

Potts RW, Gutierrez AP, Penaloza CS, Regan T, Bean TP, Houston RD. Potential of genomic technologies to improve disease resistance in molluscan aquaculture. Philos Trans R Soc B. 2021;376:20200168.

Qin Z, Li Y, Su B, Cheng Q, Ye Z, Perera DA, Fobes M, Shang M, Dunham RA. Editing of the luteinizing hormone gene to sterilize channel catfish, Ictalurus punctatus, using a modified zinc finger nuclease technology with electroporation. Mar Biotechnol. 2016;18:255-63.

Qin W, Lu X, Lin S. Programmable base editing in zebrafish using a modified CRISPR-Cas9 system. Methods. 2018;150:19-23.

Ran FA, Hsu PD, Wright J, Agarwala V, Scott DA, Zhang F. Genome engineering using the CRISPR-Cas9 system. Nat Protoc. 2013;8:2281-308.

Ravindran S. Fixing genome errors one base at a time. Nature. 2019;575:553-5.

Schmidt SM, Belisle M, Frommer WB. The evolving landscape around genome editing in agriculture: many countries have exempted or move to exempt forms of genome editing from GMO regulation of crop plants. EMBO Rep. 2020;21(6): e50680.

Simora RM, Xing D, Bangs MR, Wang W, Ma X, Su B, Khan MG, Qin Z, Lu C, Alston V, Hettiarachchi D. CRISPR/Cas9-mediated knock-in of alligator cathelicidin gene in a non-coding region of channel catfish genome. Sci Rep. 2020;10(1):1-4.

Sinclair AH, Berta P, Palmer MS, Hawkins JR, Griffiths BL, Smith MJ, Foster JW, Frischauf AM, Lovell-Badge R, Goodfellow PN. A gene from the human sex-determining region encodes a protein with homology to a conserved DNA binding motif. Nature. 1990;346:240-4.

Smith CA, Roeszler KN, Ohnesorg T, Cummins DM, Farlie PG, Doran TJ, Sinclair AH. The avian Z-linked gene DMRT1 is required for male sex-determination in the chicken. Nature. 2009:461:267-71.

Straume AH, Kjærner-Semb E, Skaftnesmo KO, Güralp H, Kleppe L, Wargelius $\mathrm{A}$, Edvardsen RB. Indel locations are determined by template polarity in highly efficient in vivo CRISPR/Cas9-mediated HDR in Atlantic salmon. Sci Rep. 2020;10:1-9.

Straume AH, Kjærner-Semb E, Skaftnesmo KO, Güralp H, Lillico S, Wargelius A, Edvardsen RB. A refinement to gene editing in Atlantic salmon using asymmetrical oligonucleotide donors. bioRxiv. 2021. https://doi.org/10. 1101/2021.02.08.430296.

Sweet JB. Draft study on risk assessment: application of annex 1 of decision CP $9 / 13$ to living modified fish. Report for the Secretariat of the Convention on Biological Diversity, UN Environmental Programme. 2019. https://bch.cbd.int/protocol/risk_assessment/report\%20-\%20study\% 20on\%20risk\%20assessment\%2020.12_final\%20for\%20posting.pdf. Accessed 5 Dec 2021

The Fish Site. Gene-edited sea bream set for sale in Japan. 22 September 2021 2021. https://thefishsite.com/articles/gene-edited-sea-bream-set-forsale-in-japan. Accessed 24 Nov 2021.

Thodesen J, Gjedrem T. Breeding programs on Atlantic salmon in Norway: lessons learned. In: Ponzoni RW, Acosta BO, Ponniah AG, editors. Development of aquatic animal genetic improvement and dissemination programs: current status and action plans. WorldFish Center Conference Proceedings. Penang:WorldFish Center. 2006;73:22-26. http:// aquaticcommons.org/2596/.

Tsuda M, Watanabe KN, Ohsawa R. Regulatory status of genome-edited organisms under the Japanese Cartagena Act. Front Bioeng Biotechnol. 2019;7:387.

USDA-NASS (U.S. Department of Agriculture-National Agricultural Statistical Service). Catfish grower and producer sales and prices. 2018. https:// www.ers.usda.gov/data-products/aquaculture-data/. Accessed 22 June 2021.

Van Eenennaam AL. Effective science communication to raise awareness on animal biotechnology. The impact of gene technology in animal agriculture and food production, virtual workshop, August 31-September1, 2021. Presentation to be posted on international service for the acquisition of agri-biotech applications website. 2021. https://www. isaaa.org/default.asp.

Wang L, Tan X, Wu Z, Wang L, Jiao S, Zou Y, Ji G, You F. Targeted mutagenesis in the olive flounder (Paralichthys olivaceus) using the CRISPR/Cas9 system with electroporation. Biologia. 2021;76:1-8.
Wargelius A. Application of genome editing in aquatic farm animals: Atlantic salmon. Transgenic Res. 2019;28:101-5.

Wargelius A, Leininger S, Skaftnesmo KO, Kleppe L, Andersson E, Taranger GL, Schulz RW, Edvardsen RB. Dnd knockout ablates germ cells and demonstrates germ cell independent sex differentiation in Atlantic salmon. Sci Rep. 2016;6:21284.

Wiedenheft B, Sternberg SH, Doudna JA. RNA-guided genetic silencing systems in bacteria and archaea. Nature. 2012;482:331-8.

Xie QP, He X, Sui YN, Chen LL, Sun LN, Wang DS. Haploinsufficiency of SF-1 causes female to male sex reversal in Nile tilapia, Oreochromis niloticus. Endocrinology. 2016;157:2500-14.

Xu X, Cao X, Gao J. Production of a mutant of large-scale loach Paramisgurnus dabryanus with skin pigmentation loss by genome editing with CRISPR/ Cas9 system. Transgenic Res. 2019;28:341-56.

Xu S, Pham TP, Neupane S. Delivery methods for CRISPR/Cas9 gene editing in crustaceans. Mar Life Sci Technol. 2020;2:1-5.

Yang Z, Yu Y, Tay YX, Yue GH. Genome editing and its applications in genetic improvement in aquaculture. Rev Aquac. 2022;14:178-91.

Yomiuri Shimbun. Kyoto firm puts genome-edited tiger puffer on the table. The Japan News, 1 November, 2021. 2021. https://the-japan-news.com/ news/article/0007936055. Accessed 3 Nov 2021.

Yu H, Li H, Li Q, Xu R, Yue C, Du S. Targeted gene disruption in Pacific oyster based on CRISPR/Cas9 ribonucleoprotein complexes. Mar Biotechnol. 2019;23:494-502.

Zhang X, Wang H, Li M, Cheng Y, Jiang D, Sun L, Tao W, Zhou L, Wang Z, Wang D. Isolation of doublesex- and Mab-3-related transcription factor 6 and its involvement in spermatogenesis in tilapia. Biol Reprod. 2014;91:1-10.

Zhang Y, Qin W, Lu X, Xu J, Huang H, Bai H, Li S, Lin S. Programmable base editing of zebrafish genome using a modified CRISPR-Cas9 system. Nat Commun. 2017:8(1):1-5.

Zhang X, Wang F, Dong Z, Dong X, Chi J, Chen H, Zhao Q, Li K. A new strain of yellow catfish carrying genome edited myostatin alleles exhibits double muscling phenotype with hyperplasia. Aquaculture. 2020;523: 735187.

Zhong Z, Niu P, Wang M, Huang G, Xu S, Sun Y, Xu X, Hou Y, Sun X, Yan Y, Wang $H$. Targeted disruption of sp7 and myostatin with CRISPR-Cas9 results in severe bone defects and more muscular cells in common carp. Sci Rep. 2016:6:22953.

Zhu B, Ge W. Genome editing in fishes and their applications. Gen Comp Endocrinol. 2018:257:3-12.

Zu Y, Zhang X, Ren J, Dong X, Zhu Z, Jia L, Zhang Q, Li W. Biallelic editing of a lamprey genome using the CRISPR/Cas9 system. Sci Rep. 2016;6:1-9.

\section{Publisher's Note}

Springer Nature remains neutral with regard to jurisdictional claims in published maps and institutional affiliations.

Ready to submit your research? Choose BMC and benefit from:

- fast, convenient online submission

- thorough peer review by experienced researchers in your field

- rapid publication on acceptance

- support for research data, including large and complex data types

- gold Open Access which fosters wider collaboration and increased citations

- maximum visibility for your research: over $100 \mathrm{M}$ website views per year

At BMC, research is always in progress.

Learn more biomedcentral.com/submissions 